\title{
Investigating Novel Thiazolyl-Indazole Derivatives as Scaffolds for SARS-CoV-2 $\mathbf{M}^{\text {Pro }}$ Inhibitors
}

Justin Airas, Catherine A. Bayas, Abdellah N'Ait Ousidi ${ }^{\dagger}$, My Youssef Ait Itto ${ }^{\dagger}$, Aziz Auhmani ${ }^{\dagger}$, Mohamed Loubidi ${ }^{\dagger}, \mathrm{M}^{\prime}$ hamed Esseffar ${ }^{\dagger}$, Julie A. Pollock, and Carol A. Parish*

Department of Chemistry, University of Richmond, Gottwald Center for the Sciences, Richmond, VA 23173

'Département de Chimie, Faculté des Sciences Semlalia, Cadi Ayyad University, BP 2390, Marrakech, Morocco

*Corresponding Author: Carol A. Parish, Department of Chemistry, Gottwald Center for the Sciences, University of Richmond, Richmond VA, USA. E-mail: cparish@richmond.edu

Keywords: SARS-CoV-2, coronavirus, COVID-19, MPro, protease, substrate, indazole, thiazolyl, thiazolyl-indazole, inhibitors, scaffold, molecular dynamics, binding assay, drug discovery

\section{Graphical Abstract}
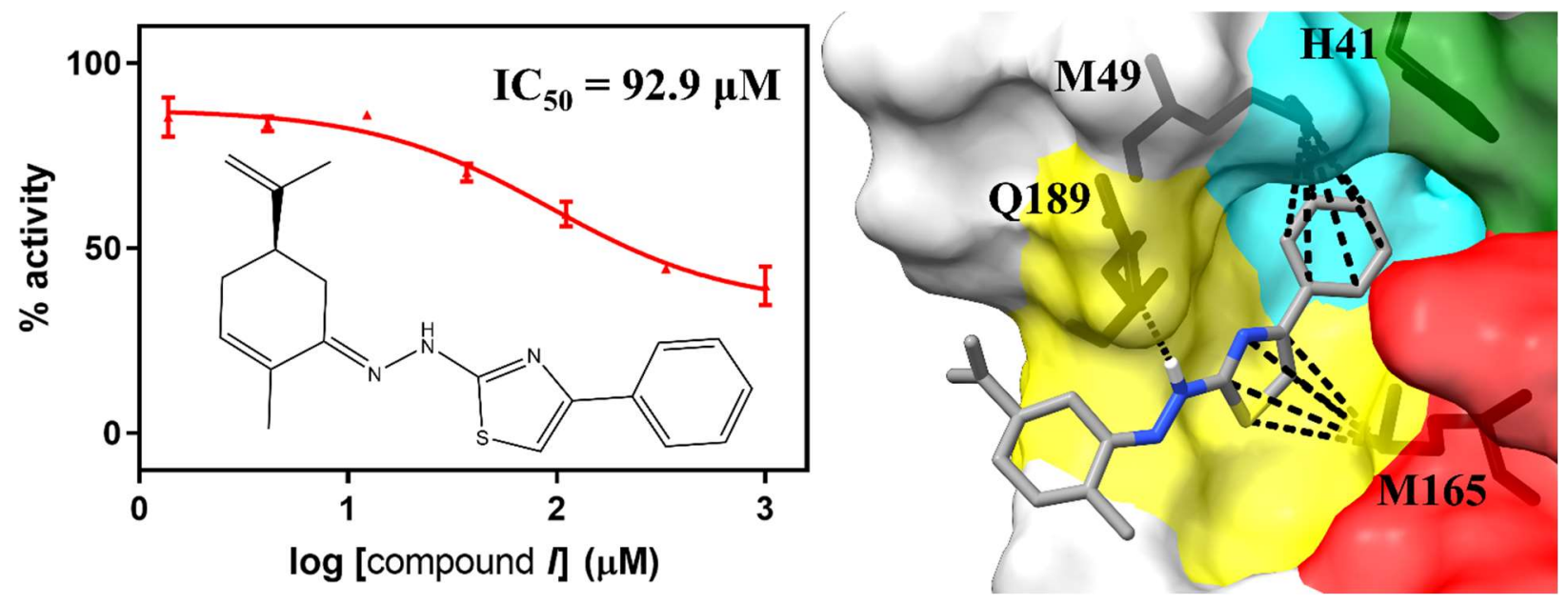

Abstract

COVID-19 is a global pandemic caused by infection with the SARS-CoV-2 virus. Remdesivir, a SARS-CoV-2 RNA polymerase inhibitor, is the only drug to have received widespread approval for treatment of COVID-19. The SARS-CoV-2 main protease 
enzyme $\left(\mathrm{M}^{\mathrm{Pro}}\right)$, essential for viral replication and transcription, remains an active target in the search for new treatments. In this study, the ability of novel thiazolyl-indazole derivatives to inhibit $\mathrm{M}^{\mathrm{Pro}}$ is evaluated. These compounds were synthesized via the heterocyclization of phenacyl bromide with $(R)$-carvone and $(R)$-pulegone thiosemicarbazones. The binding affinity and atomistic interactions of each compound were evaluated through Schrödinger Glide docking, AMBER molecular dynamics simulations, and MM-GBSA free energy estimation, and these results were compared with similar calculations of $\mathrm{M}^{\text {Pro }}$ binding various 5-mer substrates (VKLQA, VKLQS, VKLQG). From these simulations, we can see that binding is driven by residue specific interactions such as $\pi$-stacking with His41, and $S / \pi$ interactions with Met49 and Met165. The compounds were also experimentally evaluated in a $\mathrm{M}^{\text {Pro }}$ biochemical assay and the most potent compound containing a phenylthiazole moiety inhibited protease activity with an $\mathrm{IC}_{50}$ of $92.9 \mu \mathrm{M}$. This suggests that the phenylthiazole scaffold is a promising candidate for the development of future $\mathrm{M}^{\text {Pro }}$ inhibitors.

\section{Introduction}

Coronavirus disease-2019 (COVID-19) is a global pandemic caused by infection with the severe acute respiratory syndrome-coronavirus 2 (SARS-CoV-2) ${ }^{[1-4]}$ While closely related to the severe acute respiratory syndrome-coronavirus (SARS-CoV), SARS-CoV-2 demonstrates faster human transmission than both SARS-CoV and the Middle Eastern respiratory syndrome-coronavirus (MERS-CoV). ${ }^{[1-3]}$ Symptoms of COVID-19 include a cough, difficulty breathing, fever, fatigue, and loss of taste and smell that can progress to viral pneumonia in severe cases. ${ }^{[5-8]}$ A significantly higher fatality rate is noted in those above the age of 60 and those with pre-existing conditions such as cardiovascular disease, chronic lung disease, hypertension, diabetes, congestive heart failure, chronic kidney disease, and cancer. ${ }^{[7,9,10]}$ Currently, medicinal therapeutic options remain limited. 
Owing to their significance in the viral life cycle and lack of related human homologues, the SARS-CoV-2 RNA-dependent RNA polymerase (RdRp) and 3C-like main protease ( $3 \mathrm{CL}^{\mathrm{Pro}}$ or $\mathrm{M}^{\mathrm{Pro}}$ ) have been identified as potentially promising drug targets. ${ }^{[11,12]}$ The RdRp catalyzes the synthesis of viral RNA and is the target of the nucleotide analog drug remdesivir. ${ }^{[11,13]}$ With the Food and Drug Administration's Emergency Use Authorization of remdesivir, the RdRp is currently the only SARS-CoV2 drug target with an approved medicinal therapy. ${ }^{[13]} \mathrm{M}^{\text {Pro }}$, a homodimeric enzyme characterized by a catalytic His-Cys dyad, functions to cleave polyproteins pp1a and pplab at the recognition sequence Leu-Gln-|-[Ser, Ala, Gly] (-|- indicates the cleaved bond) into several nonstructural proteins essential for viral replication and transcription. ${ }^{[12,14,15]}$ This function makes $\mathrm{M}^{\text {Pro }}$ a potential target of therapeutic medicines. ${ }^{[14,16]}$

The $\mathrm{M}^{\mathrm{Pro}}$ catalytic site consists of four binding pockets or subsites. These are the S1', S1, S2, and S4 subsites, occupied by the substrate P1', P1, P2, and P4 residues, respectively. ${ }^{[12,17]}$ The His41, Val42, Asn119, Thr25, Cys145, and Gly143 sidechains and the Thr26 backbone form the S1' subsite. The S1 subsite, which accommodates the P1Gln, is formed by the Phe140, Asn142, Ser144, Cys145, His163, His172, and Glu166 sidechains and the Leu141, Gly142, His164, and Met165 backbones. The P2-Leu accommodating S2 subsite is formed by the His41, Met49, Tyr54, Met165 and Asp187 sidechains and the Arg188 and Gln189 backbone. Lastly, the S4 subsite is formed by the Met165, Leu167, Pro168, Ala191, and Gln192 sidechains and the Glu166, Arg188, and Thr190 backbones. These subsites are displayed in Figure 1. Various studies have shown that the residues forming these subsites are essential targets of $\mathrm{M}^{\text {Pro }}$ inhibitors. ${ }^{[17-24]}$ Currently no drug has been approved for $\mathrm{M}^{\text {Pro }}$ inhibition despite the screening of many structurally diverse compounds. ${ }^{[25]}$ Notable candidates have included the peptidyl Michael acceptor N3 $\left(k_{\mathrm{obs}} /[I]=11,300 \pm 880 \mathrm{M}^{-1} \mathrm{~s}^{-1}\right)$ and the broad-spectrum picoronavirus-like $\mathrm{M}^{\text {Pro }}$ inhibitor $\mathrm{GC} 376\left(\mathrm{IC}_{50}=26.4 \pm 1.1 \mathrm{nM}, K_{\mathrm{I}}=12 \pm 1.4 \mathrm{nM}\right){ }^{[12,26,27]}$ 
Both inhibitors function by covalent bond formation with the catalytic Cys 145 residue and form binding interactions with additional $\mathrm{S} 1{ }^{\prime}-\mathrm{S} 4$ subsite residues. ${ }^{[12,27-30]}$

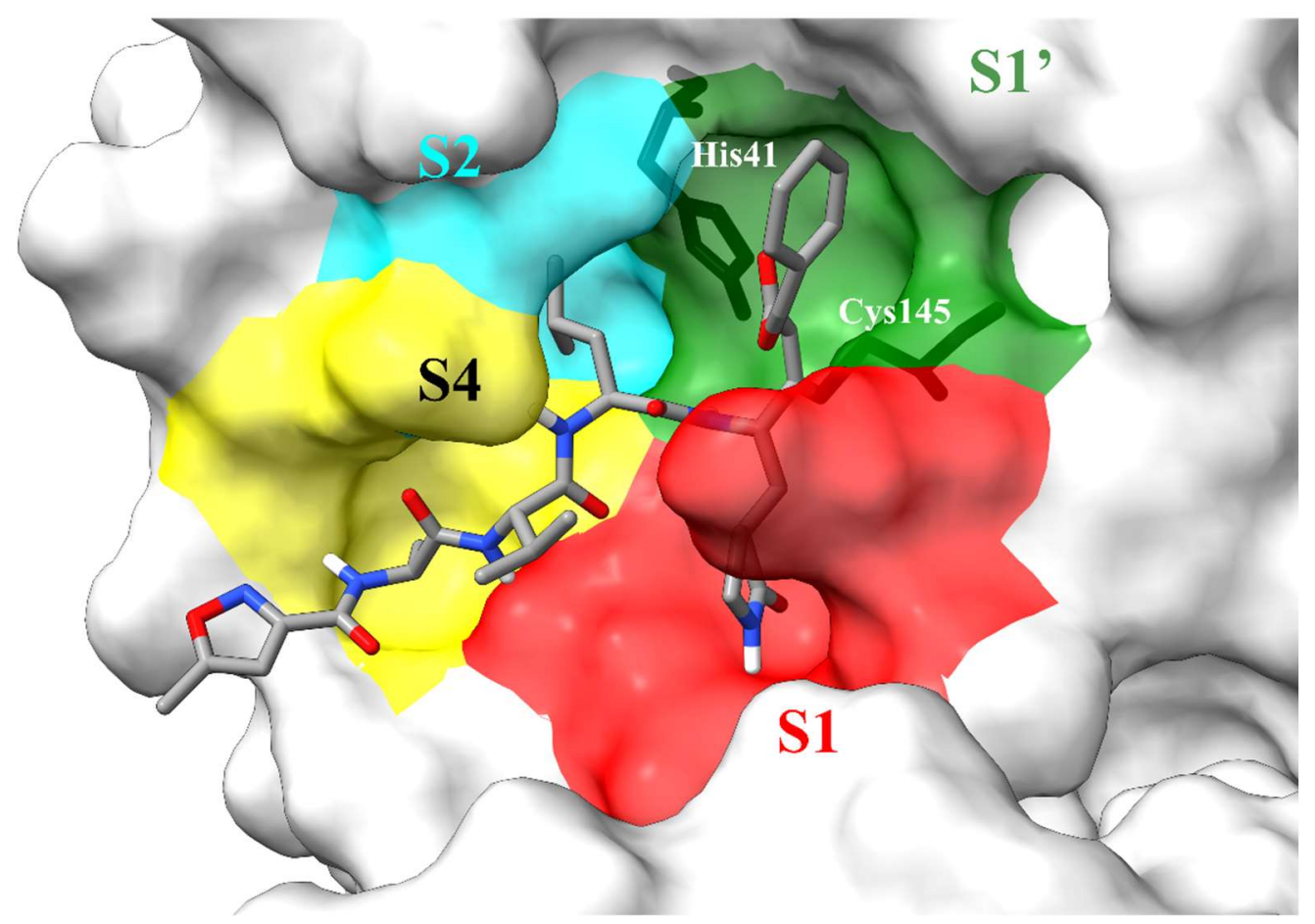

Figure 1: Subsites of the SARS-CoV-2 $\mathrm{M}^{\text {Pro }}$ with the N3 inhibitor covalently bound (PDB Code 6lu7). Subsites S1', S1, S2 and S4 are displayed in green, red, cyan, and yellow, respectively. Catalytic residues His41 and Cys145 are shown in black below the surface of the subsites.

Thiazole and indazole derivatives have displayed a wide array of biological function and there is significant interest in their pharmacologic applications. Many bioactive natural products, such as Vitamin B1, bacitracin, and penicillin contain thiazole ring structures. ${ }^{[31]}$ Additionally, synthetic thiazole-based compounds have been shown to function as antineoplastic agents, anti-HIV drugs, antifungal agents, antiparasitic agents, anti-inflammatory agents, and antiulcer agents. ${ }^{[31,32]}$ Most recently, thiazole-based inhibitors have been reported for SARS-CoV-2. ${ }^{[33,34]}$ Synthetic indazole-based compounds have exhibited function as anti-inflammatory, antiarrhythmic, antitumor, antifungal, antibacterial, and anti-HIV drugs. ${ }^{[35]}$ Indazole-based drugs are also being considered as SARS-CoV-2 $\mathrm{M}^{\text {Pro }}$ inhibitors. ${ }^{[36]}$ 
Previously, we reported the synthesis and characterization of two novel thiazolylindazole derivatives. These compounds were synthesized through the heterocyclization of phenacyl bromide with $(R)$-carvone and $(R)$-pulegone thiosemicarbazones producing $(R)$ 2-(2-(5-isopropyl-2-methylcyclohex-2-enylidene) hydrazinyl)-4-phenylthiazole $\boldsymbol{I}$ and (3aR,6R)-3,3,6-trimethyl-2-(4-phenylthiazol-2-yl)-3,3a,4,5,6,7-hexahydro-2H-indazol3a-ol II, respectively. While it was initially expected that these reactions would result in compounds $I$ and ( $R$ )-2-(2-(5-methyl-2-(propan-2-ylidene) cyclohexylidene) hydrazinyl)4-phenylthiazole $\boldsymbol{I I I}$, an unexpected rearrangement of the $(R)$-pulegone thiosemicarbazone occurred in which the thioureido group underwent an $\mathrm{N}-\mathrm{H}$ addition to the $\mathrm{C}=\mathrm{C}$ double bond. Subsequent condensation of this intermediate with phenacyl bromide followed by an unexpected oxidation reaction resulted in compound $\boldsymbol{I I}$ with two potential diastereomers $(3 a R, 6 R)$ and $(3 a S, 6 R)$. X-Ray and computational analysis indicated that the $(3 a R, 6 R)$ diastereomer was synthesized and is energetically favored. ${ }^{[37]}$ In addition to exploring the inhibitory properties of $\boldsymbol{I}-\boldsymbol{I I I}$, we are also reporting the synthesis of a version of $\boldsymbol{I I}$ lacking the hydroxy group $(\boldsymbol{I V})$, and a version of $\boldsymbol{I I I}$ with a single bond connecting the isopropyl group to the cyclohexane ring $(\boldsymbol{V})$. These compounds will provide further insight into the structural features underlying the binding of the thiazolyl-indazole derivatives. All structures are shown in Table 1.

Table 1: Structures of five thiazolyl-indazole derivatives under consideration for SARS-CoV-2 $\mathrm{M}^{\text {Pro }}$ inhibition.

Compound $I$

\section{Compound $I I I$}

\section{Compound $I V$}

\section{Compound $V$}




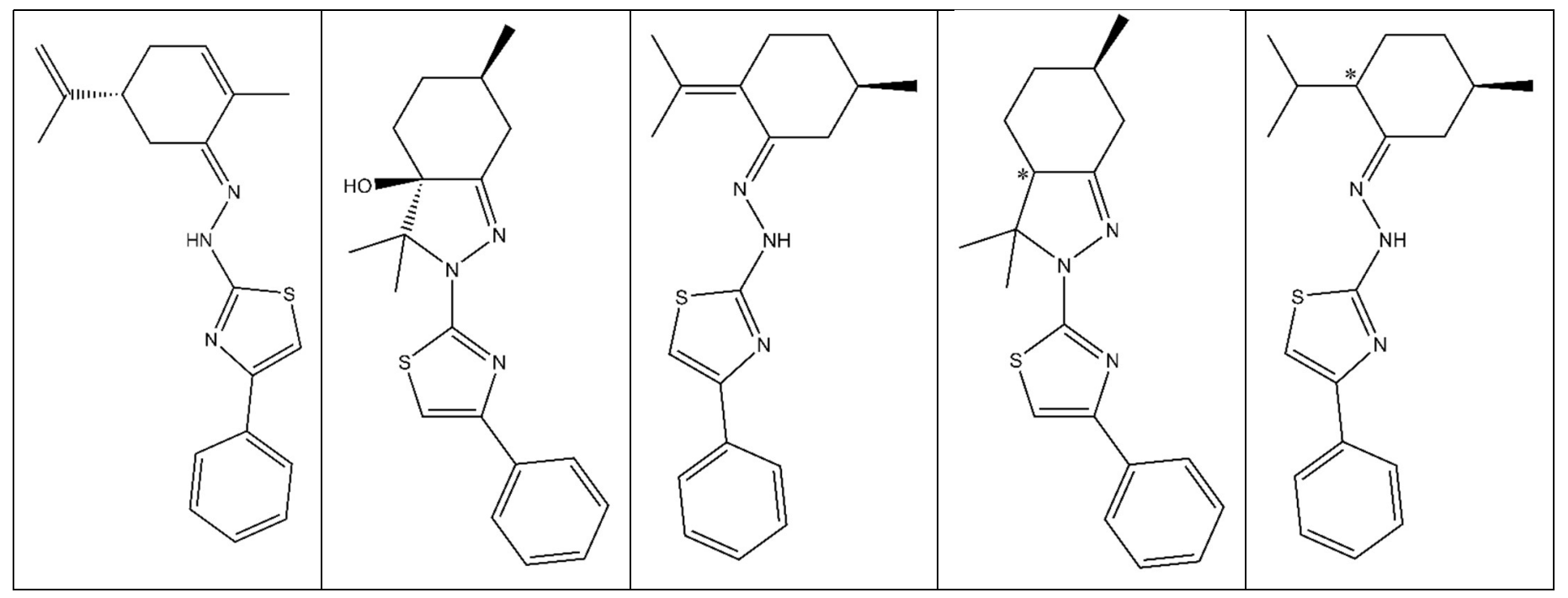

Thiazole-based compounds have shown promise as SARS-CoV $\mathrm{M}^{\text {Pro }}$ inhibitors with best-in-class compounds demonstrating $K_{I}$ values of $2.2 \mu \mathrm{M}$ and $\mathrm{IC}_{50}$ as low as 3 $\mu \mathrm{M} .{ }^{[33,34]} \mathrm{A}$ machine learning approach to identifying investigational or off-market drug targets for SARS-CoV-2 identified an indazole containing compound as one of the most promising with an estimated binding affinity of $-9 \mathrm{kcal} / \mathrm{mol} .{ }^{[36]}$ Given the wide-ranging and beneficial pharmacological impacts of thiazole- and indazole-containing compounds, and the community's interest in these drugs as potential SARS-CoV-2 $\mathrm{M}^{\text {Pro }}$ inhibitors, we seek to elucidate the usefulness of thiazolyl-indazole derivatives as potential scaffolds for further pharmaceutical development and exploration. ${ }^{[31-36,38]}$

In this work, we explore the potential for compounds $\boldsymbol{I}-\boldsymbol{V}$ to function as reversible, noncovalent inhibitors of $\mathrm{M}^{\text {Pro }}$ through chemical property prediction, biochemical assays, docking analysis, molecular dynamics simulations, and a detailed comparison with substrate binding. We have identified $\mathrm{M}^{\text {Pro }}$ amino acids that consistently interact with these compounds and our simulations reveal the importance of $\pi$ interactions in the mechanism of binding. We demonstrate experimentally that compound $\boldsymbol{I}$ is capable of inhibiting the activity of $\mathrm{M}^{\text {Pro; }}$; and this, taken together with our atomistic binding analyses, suggests that the phenylthiazole scaffold is a good candidate for future $\mathrm{M}^{\text {Pro }}$ inhibitor drug development. 


\section{Methods}

\section{Compound Property Analysis}

Two in-silico Pan-Assay Interference Compounds (PAINS) identification screens were conducted (http://www.cbligand.org/PAINS/[39] and http://zinc15.docking.org/patterns/home/) for $\boldsymbol{I}-\boldsymbol{V}$. Additionally, molecular properties and predicted absorption, distribution, metabolism, and excretion (ADME) values were calculated using Schrödinger's QikProp program. ${ }^{[40]}$ All default settings were used. In the Results section, we note any properties that violate the $95 \%$ range of known drugs.

\section{Synthesis}

Compounds $\boldsymbol{I}$ and $\boldsymbol{I I}$ have been previously reported. ${ }^{[37]}$ The synthesis of the thiazolyl-indazole heterocycles $\boldsymbol{I} \boldsymbol{V}$ and $\boldsymbol{V}$ was performed separately in a one pot reaction of the corresponding natural monoterpenic ketone, thiosemicarbazide, and the phenacyl bromide in refluxing ethanol conditions (Scheme 1).

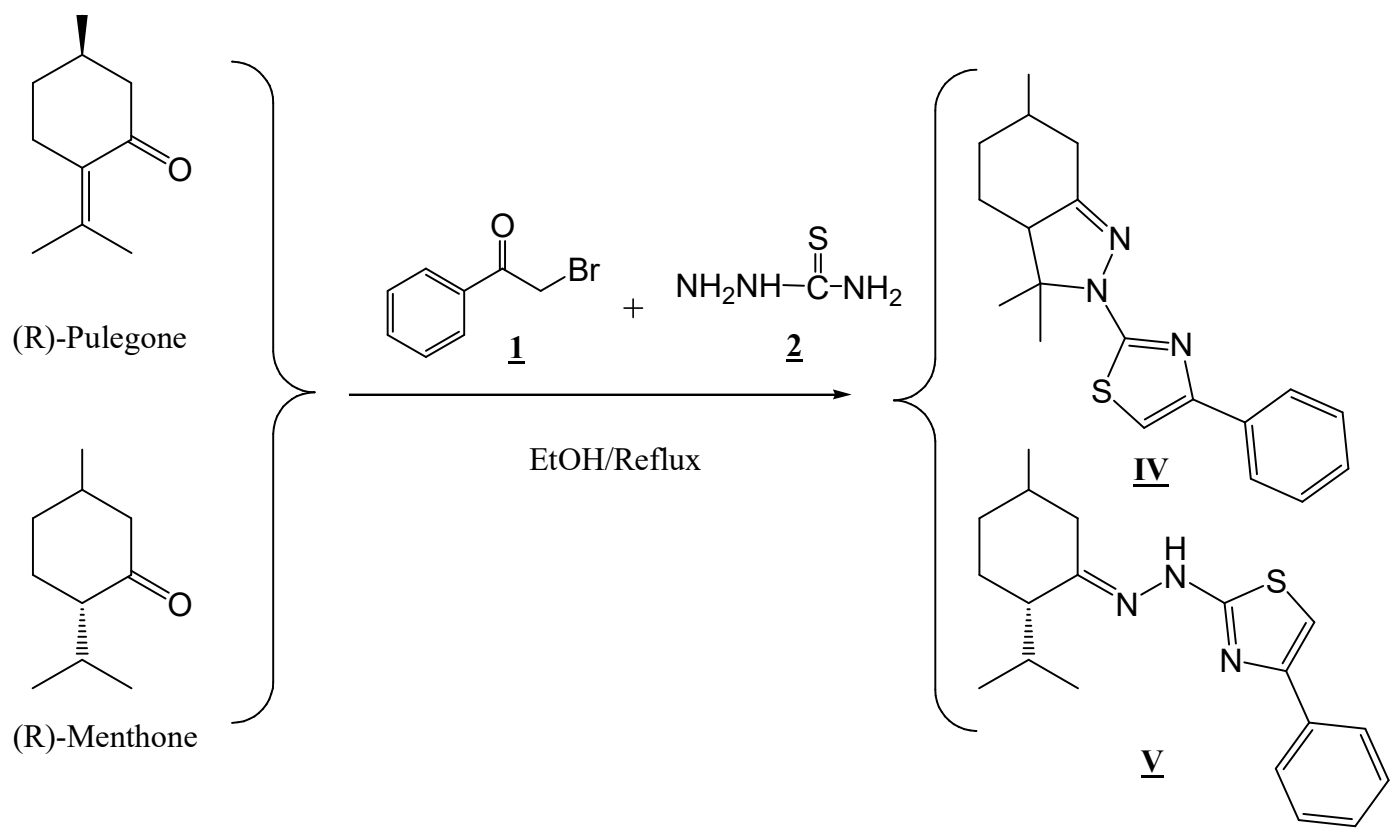

Scheme 1

The general synthetic procedure was as follows. To an ethanolic solution $(50 \mathrm{~mL}$ of absolute ethanol) 1 equivalent each of phenacyl bromide 1 and thiosemicarbazide 2 was added to 1 equivalent of $(R)$-Pulegone to produce $\boldsymbol{I} \boldsymbol{V}$ or $(R)$-Menthone to produce $\boldsymbol{V}$. 
The reaction mixture was heated under reflux for $1 \mathrm{~h}$. After evaporating the solvent, the residue was diluted with water $(10 \mathrm{~mL})$ and extracted with dichloromethane. The organic layer was separated, dried on anhydrous $\mathrm{MgSO}_{4}$, evaporated to dryness, and then purified by silica gel column chromatography, using hexane/ethyl acetate as eluent, to obtain the corresponding thiazolyl-indazole compounds in good yield (IV: 82\%; V: 70\%). The structures of the two synthesized products were confirmed based on their spectral data. The ${ }^{1} \mathrm{H}$ NMR spectra showed the appearance of the thiazolic proton $\mathrm{H}_{5}$, as a singlet at $6.82 \mathrm{ppm}$ and at $6.86 \mathrm{ppm}$ for $\boldsymbol{I}$ and $\boldsymbol{V}$, respectively (Figures S1 - S2). In addition, each compound displayed peaks in the range of $\delta_{\mathrm{H}}=7.29-7.92$ for $\boldsymbol{I}$ and $\delta_{\mathrm{H}}=7.29-7.82$ for $\boldsymbol{V}$ corresponding to a phenyl group resonance. The ${ }^{13} \mathrm{C}$ NMR spectra reveal the thiazolic carbon $\mathrm{C}_{\boldsymbol{5}}$, at $102.40 \mathrm{ppm}$ and $102.79 \mathrm{ppm}$ for $\boldsymbol{I} \boldsymbol{V}$ and $\boldsymbol{V}$, respectively (Figures $\mathrm{S} 3-\mathrm{S} 4$ ). Further NMR spectral details can be found in the Supplemental Information.

\section{Biochemical Assay}

All compounds were tested using the 3CL Protease, Untagged (SARS-CoV-2) Assay Kit (BPS Bioscience, San Diego, CA). The manufacturer's protocol was followed with slight modifications. Briefly, $5 \mathrm{X}$ serial dilutions of test compounds or inhibitor control GC376 were prepared in water. $\mathrm{M}^{\mathrm{Pro}}$ was diluted in the Assay Buffer containing 1 $\mathrm{mM}$ DTT at $0.5 \mathrm{ng} / \mu \mathrm{L}$. The diluted enzyme solution was pipetted in duplicate into a 96well half area opaque plate ( $30 \mu \mathrm{L} /$ well) while buffer alone was pipetted into "blank wells." Dilutions of compounds $\boldsymbol{I}, \boldsymbol{I I}$, and $\boldsymbol{V}, \mathrm{GC} 376$, or 5\% DMSO in water was added to wells containing the enzyme to $1 \mathrm{X}$ concentrations indicated in Figures 2, S5, and S6. and incubated at room temperature for 30 minutes with slow shaking. Protease Substrate was added to all wells and incubated with slow shaking for an additional 4 hours. Fluorescence measurements were taken using a SpectraMax i3 plate reader (Molecular Devices) with fixed excitation $(360 \mathrm{~nm})$ and emission $(460 \mathrm{~nm})$. The endpoint values were recorded using the Softmax Pro software and all raw data was normalized with the "blank" solutions. 


\section{Structure Retrieval and Preparation}

The structure of the SARS-CoV-2 $\mathrm{M}^{\text {Pro }}$ was obtained from the Protein Data Bank (PDB code 6lu7). ${ }^{[41]}$ All waters and $\mathrm{N} 3$ were removed. A dimerized model of $\mathrm{M}^{\text {Pro }}$ was created by aligning 6lu7 polypeptides to chains A and B of Human Coronavirus NL63 $\mathrm{M}^{\mathrm{Pro}}$ (PDB code 5gwy). Schrödinger's Protein Preparation Wizard was used together with Prime, Epik, and PROPKA to prepare the protein. ${ }^{[42-44]}$ Further protein preparation details can be found in the Supplemental Information. ${ }^{[42-45]}$

\section{Receptor Grid Generation, Ligand Preparation, and Glide Docking}

Schrödinger's Receptor Grid Generation program was used to generate a $40 \AA$ by $40 \AA$ by $40 \AA$ receptor grid with a ligand size cutoff of $20 \AA$. This grid was centered on the previously identified catalytic site of $\mathrm{M}^{\text {Pro }}$ and used for all subsequent ligand docking using default parameters. ${ }^{[12]}$ Structures of compound $\boldsymbol{I}-\boldsymbol{V}$ were manually built and optimized according to the GAFF force field using Avogadro 1.2. ${ }^{[46,47]}$ Geometry optimizations in PCM water at the B3LYP/6-31G* level of theory were also performed using Gaussian 16. ${ }^{[48]}$ Both diastereomers $(3 a R, 6 R)$ and $(3 a S, 6 R)$ of $\boldsymbol{I} \boldsymbol{V}$ were constructed ( $\boldsymbol{I} \boldsymbol{V}-\mathbf{E}$ and $\boldsymbol{I} \boldsymbol{V}-\mathbf{Z}$ respectively). Compound $\boldsymbol{V}$, with the exocyclic double bond removed, resulted in an altered cyclohexane structure that placed the methyl and isopropyl groups cis $(\boldsymbol{V}$-E) or trans $(\boldsymbol{V}-\mathbf{Z})$ to each other (Table 2). As such, $\boldsymbol{V}$-E and $\boldsymbol{V}-\mathbf{Z}$ were also built. Schrödinger's Glide Docking program was used to dock these molecules into the catalytic site of $\mathrm{M}^{\mathrm{Pro}} \cdot{ }^{[49,50]}$ Two poses, the primary pose $\left(1^{\circ}\right)$ that reports the most favorable GScore and an additional top scoring secondary pose $\left(2^{\circ}\right)$ with different binding interactions, were selected for further MD evaluation. Selecting poses with different binding interactions helps speed surface coverage in subsequent MD simulation. These poses and their GScores are viewable in Table S1. Additional detail on Glide docking is provided in the Supplemental Information.

\section{Substrate Preparation and Docking}

Three 5-mer P4-P3-P2-P1-|-P1' substrates, based on the best-recognized proteogenic amino acid $\mathrm{M}^{\text {Pro }}$ substrate reported by Rut et al., were built using 
Schrödinger's Maestro program. ${ }^{[1,52]}$ The C-terminal ACC dye was replaced with common P1'-site residues Ser, Ala, and Gly. ${ }^{[15]}$ To protect against the influence of terminal charges, all substrates were ACE and NME capped. The sequences of these substrates are ACE-Val-Lys-Leu-Gln-[Ser, Ala, Gly]-NME (Figure S7A). These substrates will be referred to as VKLQS, VKLQA, and VKLQG.

As with our treatment of $\boldsymbol{I}-\boldsymbol{V}$, binding site docking using the Schrödinger Glide Docking program was conducted. However, the program failed to generate poses aligning with previously described substrate recognition sequence - catalytic site interactions. ${ }^{[15,51,53]}$ Therefore, using UCSF Chimera, each substrate was manually positioned within the $\mathrm{M}^{\text {Pro }}$ catalytic site to maximize the interactions between the substrate recognition sequence residues P1-Gln and P2-Leu and the $\mathrm{M}^{\text {Pro }} \mathrm{S} 1$ and S2 pockets. ${ }^{[54]}$ The S1 and S2 pockets have been previously noted to be invariably occupied by the P1-Gln and P2-Leu residues, respectively, while low specificity is noted for the P3 and $\mathrm{P} 4$ residues. ${ }^{[51,53]}$ After manual positioning, a minimization calculation was then performed under default settings using UCSF Chimera's Minimize Structure tool. The positions of the P1-Gln and P2-Leu sidechains were fine-tuned using Schrödinger's Maestro program. ${ }^{[52]}$ Atoms/sidechains were manually moved, with localized minimizations performed with each movement. The P1-Gln sidechain was positioned to allow for contacts with Phe140, His163, and Gln166 in the S1 pocket, while the P2-Leu sidechain was moved into the S2 pocket. Additionally, the P1-Gln - P1' amide bond was positioned between catalytic residues His 41 and Cys145. Following these movements, optimization and minimization was performed using Schrödinger's Protein Preparation Wizard according to the same steps previously detailed. This resulted in a common binding pose for all three substrates. This pose is detailed in Figure S7B. Additionally, ligand interaction diagrams for each substrate are viewable in Table S2.

\section{Molecular Dynamics Simulations}

Unrestrained molecular dynamics (MD) simulations were conducted on $\mathrm{M}^{\text {Pro }}$ bound to compounds $\boldsymbol{I}-\boldsymbol{V}$ as well as the three 5-mer substrates, using the AMBER18 
suite. ${ }^{[55]}$ The $1^{\circ}$ and $2^{\circ}$ poses for $\boldsymbol{I}-\boldsymbol{V}$ were selected for MD analysis. The manually oriented binding poses detailed above were used to initiate 5-mer substrate MD. The ff14SB force field was applied to $\mathrm{M}^{\mathrm{Pro}}$ and the 5-mer substrates. ${ }^{[56]}$ The program antechamber was used to apply the GAFF force field and AM1-BCC charges to I$V^{[46,57-59]}$ All models were neutralized with $\mathrm{Na}^{+}$ions and explicitly solvated in a TIP3P unit cell using the program tleap ${ }^{[60]}$ All simulations were performed using the GPUaccelerated pmemd code of AMBER 18. ${ }^{[61,62]}$ Further details describing the MD protocol can be found in the Supplemental Information. In total, seventeen $1000 \mathrm{~ns}$ ensembles were generated (two for each compound $\boldsymbol{I}-\boldsymbol{I I I}, \boldsymbol{I V}-(\mathbf{E}, \mathbf{Z})$, and $\mathbf{V}-(\mathbf{E}, \mathbf{Z})$, and one for each of the three possible 5-mer substrates). The total number of simulations performed is detailed in Table S3.

\section{Analyses}

From each $1000 \mathrm{~ns}$ ensemble, all frames in which the ligand either sampled binding positions outside of the catalytic site or dissociated from the protein entirely where removed. All data analysis was conducted on the resultant truncated ensembles including only frames in which the ligand interacts with the catalytic site. As such, percent occurrence and thermodynamic data reported below are relative to each truncated ensemble.

Trajectory visualization was conducted using UCSF Chimera and UCSF

ChimeraX. ${ }^{[54,63]}$ MM-GBSA binding free energy, per-residue decomposition, and normal mode entropy analyses were conducted using the AmberTools MMPBSA.py package. ${ }^{[64]}$ Entropic analysis has been shown to scale binding free energies closer to experimental values while also providing improved comparison of binding affinities across models. ${ }^{[65]}$ This is especially important for comparison between diverse structures like peptide substrates and small molecule inhibitors. Entropy calculations were performed on each truncated ensemble of $\boldsymbol{I}$ and $\boldsymbol{I I I}$ (with $\boldsymbol{I I}, \boldsymbol{I V}$ and $\boldsymbol{V}$ excluded due to experimental and computational shortcomings reported in the Results section) with a $12.5 \mathrm{~ns}$ interval. Hydrogen bonding, center-of-mass distance ( $\mathrm{COM})$, and root-mean-squared deviation 
(RMSD) analyses were conducted on $\boldsymbol{I}$ - III using the AmberTools cpptraj module. Potential aromatic $-\pi$ interactions were screened using literature-based COM distance cutoffs as detailed in Table S4. ${ }^{[66-71]}$

Ensemble averaged binding structures were created for the $\boldsymbol{I}-\boldsymbol{I I I}$ truncated ensembles using cpptraj RMSD-based clustering. Compounds $\boldsymbol{I}$ and $\boldsymbol{V}$ were excluded from this analysis due to shortcomings relative to $\boldsymbol{I}-\boldsymbol{I I I}$. The RMSD of each frame within each ensemble relative to its respective average binding structure was then calculated. Frames reporting an RMSD value below $1.75 \AA$ were considered to sample the average structure. This cutoff value, intended to account for the dynamic behavior of each structure, was determined from trajectory visualization. Note that the percent occurrence of a structure that undergoes more fluctuation will be underreported. When RMSD analysis alone is deemed insufficient, center-of-mass (COM) analysis is additionally used with cutoff distances selected on a case-by-case basis.

\section{Results and Discussion}

\section{PAINS and QikProp Analysis}

All compounds passed both PAINS screens with no points of concern. There were no $95 \%$ range violations or reactive functional groups reported for $\boldsymbol{I}-\boldsymbol{I I I}$, however $\boldsymbol{I V}$ and $\boldsymbol{V}$ generated range violations, and ADME screening indicated a reactive functional group in $\boldsymbol{V}$. Aqueous solubilities for $\boldsymbol{I I}, \boldsymbol{I I I}$ and $\boldsymbol{V}$-E lie notably close to the $\log \mathrm{S}-6.5$ lower limit, while both isomers of $\boldsymbol{I} \boldsymbol{V}$ and $\boldsymbol{V}-\mathbf{Z}$ exceed it. Predicted brain / blood partition coefficients show that $\boldsymbol{I}$ displays the lowest potential for CNS activity while $\boldsymbol{I I I}$ and $\boldsymbol{I V}$

display the most. All compounds have predicted HERG $\mathrm{K}^{+}$channel $\log \mathrm{IC}_{50}$ values below -5 and as such are flagged as potential concerns. Compound $\boldsymbol{I I I}$ and $\boldsymbol{V}-\mathbf{Z}$ report the largest potential for HERG $\mathrm{K}^{+}$channel blockage. It should be noted that this does not necessarily suggest that these or other thiazolyl-indazole compounds are not viable drug candidates. As noted in the QikProp version 6.1 User Manual, failed drug candidates displaying QT-prolongation issues exhibit a large range of $\mathrm{IC}_{50}$ values, with cisapride 
( $\left.\mathrm{IC}_{50} 6.5 \mathrm{nM}, \log \mathrm{IC}_{50}-8.187\right)$ and grepafloxacin $\left(\mathrm{IC}_{50} 50000 \mathrm{nM}, \log \mathrm{IC}_{50}-4.301\right)$ noted as examples. Ultimately, drug compound class, required dosage, and bioavailability determine the allowable $\mathrm{IC}_{50}$ limit. ${ }^{[40]}$ Taken together, these results suggest that $\boldsymbol{I}$ displays the most favorable drug-like properties.

Table 2: Molecular properties and ADME values predicted by QikProp. Starred values fall outside of the $95 \%$ range of known drugs. The potential for QT-prolongation issues is noted, with QikProp flagging predicted logIC ${ }_{50}$ values below -5 ( $\mathrm{IC}_{50}$ of $\left.10000 \mathrm{nM}\right)$. Approximate $\mathrm{IC}_{50}$ values for each compound were calculated.

\begin{tabular}{|c|c|c|c|c|c|c|c|c|}
\hline Cmpd. & MW (Da) & $\begin{array}{c}\text { H-Bond } \\
\text { Donor }\end{array}$ & $\begin{array}{c}\text { H-Bond } \\
\text { Acceptor }\end{array}$ & $\begin{array}{c}\text { logP } \\
\text { Octanol/ } \\
\text { Water }\end{array}$ & $\begin{array}{c}\text { logS } \\
\text { Aqueous } \\
\text { Solubility }\end{array}$ & $\begin{array}{c}\text { logBB } \\
\text { Brain / } \\
\text { Blood }\end{array}$ & $\begin{array}{c}\text { logIC } \\
\text { HERG }\end{array}$ & $\begin{array}{c}\text { IC }_{50}(\mathbf{n M}) \\
\text { HERG K}^{+}\end{array}$ \\
\hline $\boldsymbol{I}$ & 323.455 & 1 & 3.50 & 4.749 & -5.203 & -0.001 & -5.275 & $\sim 5308.8$ \\
\hline $\boldsymbol{I I}$ & 341.470 & 1 & 3.25 & 4.943 & -6.329 & 0.165 & -5.363 & $\sim 4335.1$ \\
\hline $\boldsymbol{I I I}$ & 325.471 & 1 & 3.50 & 5.228 & -6.182 & 0.308 & -5.666 & $\sim 2157.7$ \\
\hline $\boldsymbol{I} \boldsymbol{V}$-E & 325.471 & 0 & 2.50 & 5.471 & $-6.739^{*}$ & 0.449 & -5.423 & $\sim 3775.7$ \\
\hline $\boldsymbol{I} \boldsymbol{V}-\mathbf{Z}$ & 325.471 & 0 & 2.50 & 5.496 & $-6.773^{*}$ & 0.453 & -5.447 & $\sim 3572.7$ \\
\hline $\boldsymbol{V}$-E & 327.487 & 1 & 3.50 & 5.269 & -6.241 & 0.234 & -5.547 & $\sim 2837.9$ \\
\hline $\boldsymbol{V}$-Z & 327.487 & 1 & 3.50 & 5.188 & $-6.510^{*}$ & 0.147 & -5.924 & $\sim 1191.2$ \\
\hline
\end{tabular}

Property analysis largely eliminates $\boldsymbol{I} \boldsymbol{V}-(\mathbf{E}, \mathbf{Z})$ and $\boldsymbol{V}-(\mathbf{E}, \mathbf{Z})$ as potential drug candidates, as both display shortcomings relative to $\boldsymbol{I}-\boldsymbol{I I I}$. ADME screening indicates that the removal of the hydroxy group from $\boldsymbol{I I}$, to form $\boldsymbol{I V}$, results in $\boldsymbol{I V}$ having an aqueous solubility outside the $95 \%$ range of known drug-like molecules, along with an increased potential for CNS activity and HERG $\mathrm{K}^{+}$channel blockage. This suggests that the hydroxy group of II may be necessary for maintaining drug-like properties. Likewise, ADME screening indicates that removal of the isopropyl - cyclohexane double bond in III to produce $\boldsymbol{V}$ results in the cyclohexane - linking imine becoming a potentially reactive carbonyl center (Table 2). 


\section{Biochemical Evaluation}

In order to evaluate the ability of the compounds to disrupt the activity of $\mathrm{M}^{\text {Pro }}$, we employed a commercially available kit (see methods). We confirmed the validity of the assay using the known covalent inhibitor GC376 obtaining an $\mathrm{IC}_{50}$ of $32.5 \mathrm{nM}$, similar to literature values (Figure S5). ${ }^{[27]}$ Since the assay relies on the cleavage of an internally quenched EDANS fluorophore $\left(\lambda_{\text {ex }} 360 \mathrm{~nm}, \lambda_{\mathrm{em}} 460 \mathrm{~nm}\right)$, we first examined the background fluorescence of the synthesized compounds $I, I I, I V$, and $V$. As seen in Figure S8, compound $\boldsymbol{I} \boldsymbol{V}$ exhibited high fluorescence when excited at $360 \mathrm{~nm}$ so it was excluded from biological testing. Due to solubility issues, we were only able to test compounds $\boldsymbol{I I}$ and $\boldsymbol{V}$ up to $100 \mu \mathrm{M}$ and did not observe inhibition of $\mathrm{M}^{\text {Pro }}$ activity at these concentrations (Figure S6). There were no solubility issues with compound $\boldsymbol{I}$, in agreement with our ADME prediction that $\boldsymbol{I}$ is the most water soluble while $\boldsymbol{I I}-\boldsymbol{V}$ lie close to or even surpass the $95 \%$ solubility range of known drug-like molecules, and therefore we were able to characterize the inhibitory activity (Figure 2, $\mathrm{IC}_{50} 92.9 \mu \mathrm{M}$ ).

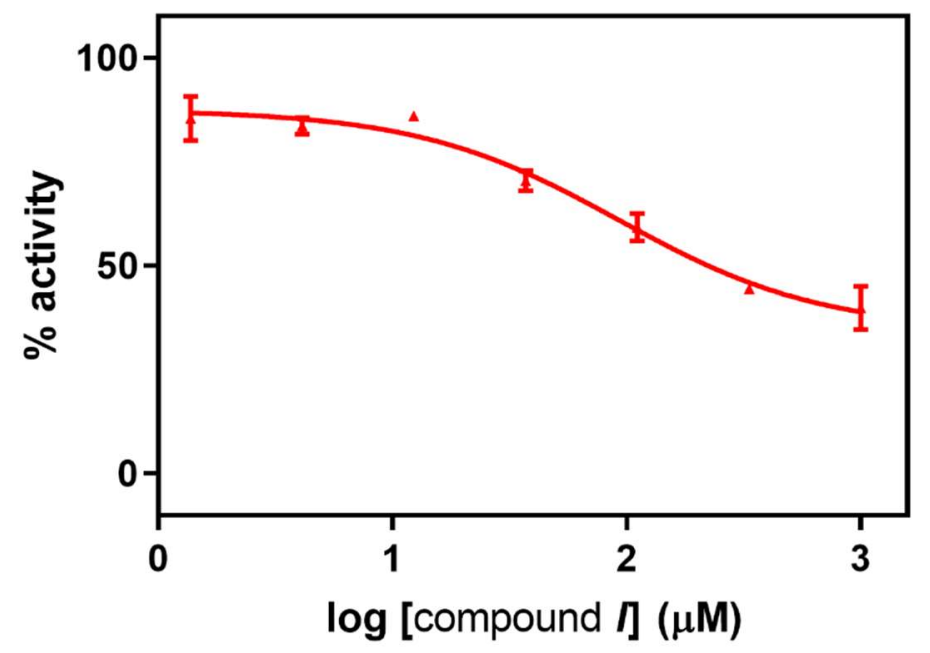

Figure $2: \mathrm{M}^{\text {Pro }}$ activity at varying concentrations of compound $\boldsymbol{I}$. Fluorescence intensity $\left(\lambda_{\mathrm{ex}} 360 \mathrm{~nm}, \lambda_{\mathrm{em}} 460 \mathrm{~nm}\right)$ was measured after 4 hours of reaction time as described in the methods and normalized by subtracting the blank and dividing by the $0 \mu \mathrm{M}$ control. The curve was fit in GraphPad Prism to give an $\mathrm{IC}_{50}$ of $92.9 \mu \mathrm{M}$ ( $95 \%$ confidence interval 55.2 to $158.6 \mu \mathrm{M})$. 


\section{Molecular Dynamics Analysis}

To better understand the atomistic nature of the experimental results, MD simulations of each compound bound to $\mathrm{M}^{\mathrm{Pro}}$ were conducted, resulting in the production of a $1000 \mathrm{~ns}$ ensemble each for the $1^{\circ}$ and $2^{\circ}$ Glide poses. Initial data analysis began with the removal of frames where the compound either dissociated from $\mathrm{M}^{\text {Pro }}$ or sampled a binding position outside of the His-Cys catalytic site. A simple analysis based solely on the percentage of frames of $\boldsymbol{I}-\boldsymbol{V}$ that dissociated from $\mathrm{M}^{\text {Pro }}$ suggest that $\boldsymbol{I}, \boldsymbol{I I I}$ and $\boldsymbol{V}-\boldsymbol{Z}$ show promise as good binders (Table 3). Increased dissociation of $\boldsymbol{I I}$ and $\boldsymbol{I} \boldsymbol{V}$ is likely the result of increased structural rigidity caused by the presence of the indazole group. Trajectory visualization suggests that this increased rigidity results in a diminished ability of $\boldsymbol{I I}$ and $\boldsymbol{I V}$ to conform to catalytic site dynamics. To further evaluate binding, we calculated MM-GBSA binding free energies and average structures for $\boldsymbol{I}-\boldsymbol{V}$ using truncated ensembles that included only frames where ligand dissociation did not occur (Table 3). Taken together, the estimated binding free energies, percent dissociation values, and properties prediction suggest that $\boldsymbol{I}, \boldsymbol{I I I}$ and $\boldsymbol{V}-\boldsymbol{Z}$ show the most promise as potential inhibitors. This agrees with our experimental results for $\boldsymbol{I}$; unfortunately, we were unable to synthesize $\boldsymbol{I I I}$ for experimental testing, and $\boldsymbol{V}$ did not show inhibition at concentrations lower than $100 \mu \mathrm{M}$. Limited solubility of $\boldsymbol{V}$ prevented us from testing at higher concentrations. It is noteworthy that our synthesis of $\boldsymbol{V}$ produced both the $\mathrm{E}$ and $\mathrm{Z}$ isomers and so it is possible that our experimental binding analysis at these concentrations was diminished by the presence of the $\mathrm{E}$ isomer. Data for each individual seed and the full non-truncated $1000 \mathrm{~ns}$ ensembles is detailed in Tables S5 - S7.

Table 3: Full ensemble percent dissociations and truncated ensemble binding free energies for $\boldsymbol{I}-\boldsymbol{V}$. Frames encompassed by the full ensemble $\%$ dissociation $[\mathrm{A}]$ were removed, and the remaining frames $[\mathrm{B}]$ were used to create truncated ensembles. MM-GBSA binding free energies for the frames of these truncated ensembles and their standard errors are reported.

\begin{tabular}{|c|c|c|c|c|}
\hline \multirow[t]{2}{*}{ Compound } & \multirow[t]{2}{*}{ Ensemble } & \multirow{2}{*}{$\begin{array}{c}\text { \% Dissociation }^{[\mathrm{A}]} / \\
\text { \% Truncated Ensemble } \\
{[\mathrm{B}]}\end{array}$} & \multicolumn{2}{|c|}{$\Delta \Delta \mathbf{G}(\mathrm{kcal} / \mathrm{mol})$} \\
\hline & & & Avg. & Std. Err. \\
\hline$I$ & $1^{\circ}$ & $19.0 / 81.0$ & -25.56 & 0.06 \\
\hline
\end{tabular}




\begin{tabular}{|c|c|c|c|c|}
\hline & $2^{\circ}$ & $6.0 / 94.0$ & -26.83 & 0.05 \\
\hline \multirow[t]{2}{*}{ II } & $1^{\mathrm{o}}$ & $29.0 / 71.0$ & -26.21 & 0.07 \\
\hline & $2^{\circ}$ & $12.9 / 87.1$ & -24.66 & 0.05 \\
\hline \multirow[t]{2}{*}{ III } & $1^{\mathrm{o}}$ & $10.5 / 89.5$ & -29.51 & 0.07 \\
\hline & $2^{\circ}$ & $9.4 / 90.6$ & -26.09 & 0.07 \\
\hline \multirow[t]{2}{*}{$I V$-E } & $1^{\circ}$ & $28.2 / 71.8$ & -24.23 & 0.08 \\
\hline & $2^{\circ}$ & $50.8 / 49.2$ & -26.16 & 0.10 \\
\hline \multirow[t]{2}{*}{$I V-Z$} & $1^{\circ}$ & $39.3 / 60.7$ & -23.04 & 0.07 \\
\hline & $2^{\circ}$ & $20.0 / 80.0$ & -24.37 & 0.05 \\
\hline \multirow[t]{2}{*}{$V-\mathbf{E}$} & $1^{\circ}$ & $38.7 / 61.3$ & -24.99 & 0.07 \\
\hline & $2^{\circ}$ & $38.3 / 61.7$ & -22.73 & 0.07 \\
\hline \multirow[t]{2}{*}{$V-Z$} & $1^{\circ}$ & $11.8 / 88.2$ & -27.13 & 0.07 \\
\hline & $2^{\circ}$ & $23.9 / 76.1$ & -23.37 & 0.07 \\
\hline
\end{tabular}

Compound $\boldsymbol{V}$ is not likely to be a viable candidate due to its physical properties; however, a comparison to the results obtained with this molecule provide structural insight into the role of the exocyclic isopropyl moiety on the binding of $\boldsymbol{I}$ and $\boldsymbol{I I I}$. While our trajectory analysis of $\boldsymbol{I}$ and $\boldsymbol{I I I}$ does not provide evidence of any specific interactions between the isopropyl - cyclohexane double bond and the $\mathrm{M}^{\text {Pro }}$ catalytic site (see below), the slightly reduced MM-GBSA binding estimations for $\boldsymbol{V}$ suggest that the positioning of the isopropyl group and overall conformation of the cyclohexane ring in $\boldsymbol{I}$ and $\boldsymbol{I I I}$ affect binding affinity. It is notable that $\boldsymbol{I}$, with its non-planar isopropyl group, displays a somewhat less favorable binding affinity and higher percent dissociation than $\boldsymbol{I I I}$ which has a planar isopropyl. Likewise, $\boldsymbol{V}$-E with a non-planar isopropyl oriented similarly to $\boldsymbol{I}$, displays a less favorable binding affinity and higher percent dissociation than the $\boldsymbol{V}-\mathbf{Z}$ enantiomer with the isopropyl group oriented to the opposite side of the molecule. These results suggest that the orientation of the isopropyl is important and that a cis-oriented isopropyl may be less suitable than a planar or trans-oriented isopropyl.

It is similarly possible that the presence of the double bond in or adjacent to the cyclohexane group affects binding affinity. Geometry optimizations performed on $\boldsymbol{I}$ at the 
B3LYP/6-31G* level of theory in solvent (PCM water) indicate that this ring is largely planar with a pucker at the isopropyl group. The cyclohexane of $\boldsymbol{I I I}$ is also largely planar, however the pucker is more pronounced and present at the two cyclohexane carbons between the methyl and isopropyl groups. Keeping in mind that $\boldsymbol{I I}$ and $\boldsymbol{V}$ did not produce inhibition in our experimental studies, it is notable that the cyclohexane ring in $\boldsymbol{I I}$ is a chair-like whereas in $\boldsymbol{V}-\mathbf{E}$ and $\boldsymbol{V}-\mathbf{Z}$ the cyclohexane adopts twisted boat- and chair-like conformations, respectively (Table 3). Taken together, our experimental binding results and molecular modeling suggests that some planarity in the cyclohexane ring may be important to binding.

Per-residue energy decomposition analysis was conducted on each truncated ensemble of $\boldsymbol{I}$ - III (Table 4). Compound $\boldsymbol{I I}$ was included for comparison to $\boldsymbol{I}$ and $\boldsymbol{I I I}$, even though $\boldsymbol{I I}$ did not show good binding at lower concentrations. The catalytic His41, and Met49, Met165, and Gln189 report highly favorable decomposition energies across all compounds, suggesting their importance for binding interactions. Apart from Gln189, these interactions are largely driven by van der Waals effects.

Table 4: MM-GBSA per-residue total energy decomposition across all compounds/ensembles. All residues with an average total energy contribution of $<-0.5 \mathrm{kcal} / \mathrm{mol}$ are shown. Similarly, if a residue contributed an average total energy of $>-0.5 \mathrm{kcal} / \mathrm{mol}$ for a particular ensemble, that energy is not reported. The four bolded residues, His 41 , Met49, Met165, and Gln189 are shown to contribute energy decompositions important for binding across all compounds and truncated ensembles.

\begin{tabular}{|c|c|c|c|c|c|c|}
\hline \multirow[t]{2}{*}{ Residue } & \multicolumn{6}{|c|}{ Average Total Energy Decomposition (kcal/mol) } \\
\hline & $I 1^{\circ}$ & $I 2^{\circ}$ & II $1^{\circ}$ & II $2^{\circ}$ & III $1^{\circ}$ & III $2^{\circ}$ \\
\hline Leu27 & - & - & - & $-0.75 \pm 0.38$ & - & $-0.85 \pm 0.54$ \\
\hline His41 & $-1.14 \pm 0.74$ & $-1.11 \pm 0.54$ & - & $-2.13 \pm 0.75$ & $-1.05 \pm 0.61$ & $-2.24 \pm 1.41$ \\
\hline Met49 & $-1.47 \pm 0.95$ & $-0.89 \pm 0.68$ & $-0.52 \pm 0.53$ & $-1.51 \pm 0.96$ & $-1.04 \pm 0.62$ & $-1.73 \pm 0.78$ \\
\hline Leu141 & - & - & - & - & $-1.27 \pm 0.91$ & - \\
\hline Asn 142 & - & - & $-1.46 \pm 1.95$ & - & $-0.92 \pm 0.71$ & - \\
\hline Gly143 & - & - & $-0.69 \pm 1.12$ & - & - & - \\
\hline Ser144 & - & - & $-0.70 \pm 0.71$ & - & $-0.88 \pm 0.57$ & - \\
\hline Cys145 & - & - & $-0.52 \pm 0.59$ & $-0.63 \pm 0.40$ & $-0.64 \pm 0.49$ & $-0.60 \pm 0.38$ \\
\hline
\end{tabular}




\begin{tabular}{|c|c|c|c|c|c|c|}
\hline His164 & - & - & - & - & $-1.66 \pm 1.35$ & - \\
\hline Met165 & $\mathbf{- 1 . 3 1} \pm \mathbf{0 . 6 4}$ & $\mathbf{- 1 . 4 9} \pm \mathbf{0 . 9 0}$ & $\mathbf{- 1 . 7 1} \pm \mathbf{1 . 3 7}$ & $\mathbf{- 1 . 3 3} \pm \mathbf{0 . 7 3}$ & $\mathbf{- 1 . 8 2} \pm \mathbf{0 . 8 0}$ & $\mathbf{- 1 . 3 6} \pm \mathbf{0 . 8 7}$ \\
\hline Glu166 & - & - & $-0.68 \pm 1.04$ & - & $-0.83 \pm 1.49$ & - \\
\hline Asp187 & $-1.07 \pm 0.56$ & $-0.84 \pm 0.63$ & - & $-0.83 \pm 0.70$ & - & - \\
\hline Gln189 & $\mathbf{- 1 . 6 3} \pm \mathbf{1 . 2 4}$ & $\mathbf{- 2 . 2 6} \pm \mathbf{0 . 9 9}$ & $\mathbf{- 1 . 1 5} \pm \mathbf{1 . 3 2}$ & $\mathbf{- 0 . 8 1} \pm \mathbf{1 . 1 1}$ & $\mathbf{- 0 . 6 0} \pm \mathbf{0 . 8 2}$ & $\mathbf{- 0 . 9 8} \pm \mathbf{1 . 1 6}$ \\
\hline
\end{tabular}

Visualization of the truncated ensembles suggests close interactions between many of the above residues and the phenyl and thiazole groups of $\boldsymbol{I}-\boldsymbol{I I I}$. To further elucidate the importance of this interaction, COM distance analysis was conducted between these aromatic rings and the functional groups of the noted sidechains of $\boldsymbol{I}$ - III (Table S12). This analysis suggests the occurrence of various interactions, most notably $\pi$-stacking interactions with His41, and S/ $\pi$ interactions with Met49 and Met165. These compounds display similar per-residue decomposition profiles, and thus the occurrence of similar $\pi$ interactions is not surprising. Additionally, the potential for $\mathrm{OH} / \pi$ interactions with Ser144, SH/ $\pi$ interactions with Cys 145 , and anion/ $\pi$ interactions with Glu166 are noted with $\boldsymbol{I I}$ and $\boldsymbol{I I I}$. These Glu166 interactions resemble Asp anion/ $\pi$ interactions reported in the work Ellenbarger et al. (face-on packing to the aromatic $\pi$-cloud). ${ }^{[72]}$ The $\mathrm{Cys} \mathrm{SH} / \pi$ interaction occurs only with $\boldsymbol{I I}$, while potential Ser $\mathrm{OH} / \boldsymbol{\pi}$ interactions occur only with the phenyl group of $\boldsymbol{I I}$ and with the thiazole of $\boldsymbol{I I I}$. While the interactions in $\boldsymbol{I I}$ suggest promise for the indazole scaffold as the basis of a potential $\mathrm{M}^{\text {Pro }}$ inhibitor, we do not see experimental inhibition at lower concentrations. In addition to the $\pi / \pi, \mathrm{S} / \pi, \mathrm{OH} / \pi$ and anion $/ \boldsymbol{\pi}$ interactions, we also looked at hydrogen bonding patterns for the binding of $\boldsymbol{I}$. Compound $\boldsymbol{I}$ donates a hydrogen bond to $\mathrm{Gln} 189$ for $28.56 \%$ of the truncated ensembles, in agreement with the decomposition energies reported in Table 4. Solvent-bridged hydrogen bonds are additionally noted with Glu166 (11.17\%) and Gln189 (9.33\%). Hydrogen bonding patterns for $\boldsymbol{I}-\boldsymbol{I I I}$ can be found in the Supplemental Information (Tables S13 - S14). 


\section{Average Binding Structures of $I$ and $I I I$}

Compound $\boldsymbol{I}$ has experimentally verified $\mathrm{M}^{\text {Pro }}$ binding behavior suggesting that it may prove useful as an inhibitor scaffold for future development. Compound $\boldsymbol{I I I}$ is experimentally untested, but our computational results and the similarity of the underlying thiazole backbone structure with $\boldsymbol{I}$ warrants its inclusion for further structural analysis. Within each truncated ensemble of $\boldsymbol{I}$ and $\boldsymbol{I I I}$, an average binding structure within the His-Cys catalytic site was identified through cpptraj analysis. These structures, visualized in Figure 3, provide deeper insight to the per-residue decomposition energetics and potential $\pi$ interactions. Three average binding structures were identified for $\boldsymbol{I}$, while two were identified for $\boldsymbol{I I I}$. These structures are described as dominant or non-dominant, with the dominant structure reporting the higher percent occurrence. Collectively, the dominant and non-dominant average structures shown in Figure 3 represent 93.16 and $60.99 \%$ of frames within the $\boldsymbol{I}$ and $\boldsymbol{I I I}$ ensembles, with the remaining frames sampling disordered binding interactions. RMSD and COM graphs visualizing the percent occurrence of these structures over each ensemble are viewable in Figures S9 - S13. MM-GBSA binding free energy analysis of only the frames sampling these average structures was conducted (Figure 3B). The binding free energy of the $\boldsymbol{I}$ dominant structure closely matches the $I$ average $\Delta \Delta \mathrm{G}$ (-26.46 vs. $-26.24 \mathrm{kcal} / \mathrm{mol})$. Most notably, both average structures of $\boldsymbol{I I I}$ report $\Delta \Delta \mathrm{G}$ 's more favorable than the $\boldsymbol{I I I}$ average $\Delta \Delta \mathrm{G}$ (30.93 and -29.27 , vs. $-27.79 \mathrm{kcal} / \mathrm{mol}$ ). This suggests increased binding affinity of the $\boldsymbol{I I I}$ average structures over disordered binding interactions. 


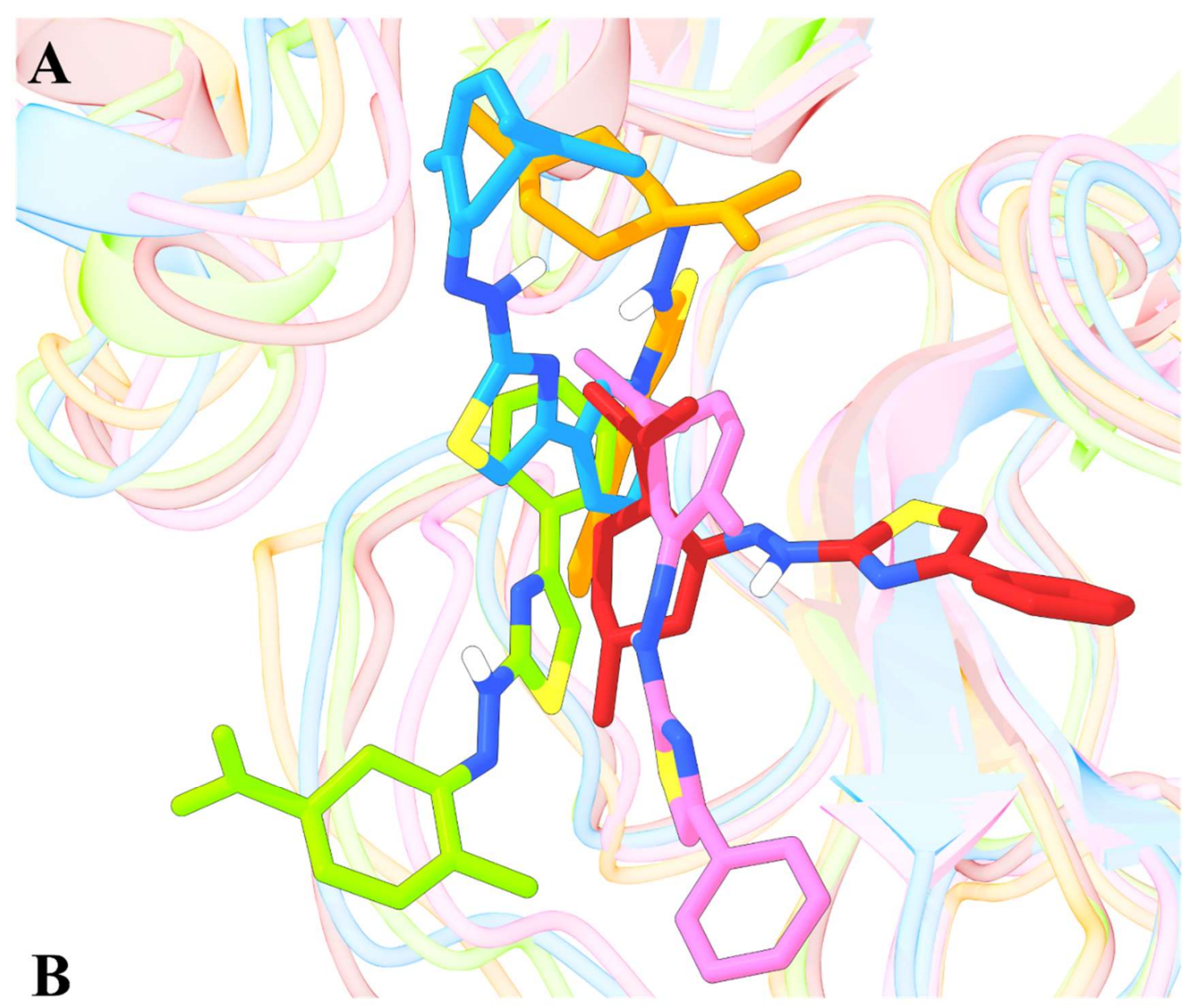

\section{Color Cmpd. Ensemble $\% \quad \Delta \Delta \mathbf{G}(\mathrm{kcal} / \mathrm{mol})$ Occurrence Avg. Std. Err.}

\begin{tabular}{ccccc}
\hline $\boldsymbol{I}$ & $1^{\mathrm{o}} \& 2^{\mathrm{o}}$ & 56.34 & -26.46 & 0.05 \\
$\boldsymbol{I}$ & $1^{\mathrm{o}}$ & 22.20 & -24.68 & 0.09 \\
$\boldsymbol{I}$ & $2^{\mathrm{o}}$ & 14.62 & -28.46 & 0.11 \\
$\boldsymbol{I I I}$ & $1^{\mathrm{o}}$ & 36.48 & -30.93 & 0.05 \\
$\boldsymbol{I I I}$ & $2^{\mathrm{o}}$ & 24.51 & -29.27 & 0.07
\end{tabular}

Figure 3: A. Average binding structures of $\boldsymbol{I}$ and $\boldsymbol{I I I}$ within the $\mathrm{M}^{\text {Pro }}$ catalytic site. B. A table providing a color key and indicating which ensemble each structure shown in $\mathbf{A}$ was found in. The overall \% occurrence of each average structure is reported, along with the MM-GBSA binding free energies of only the frames sampling these binding structures. 
Differences between the three average structures of $\boldsymbol{I}$ are noted in Figures 3 and 4 . RMSD visualization in Figure S9 indicates that sampling of the $\boldsymbol{I}$ non-dominant structures (22.20 and $14.62 \%$ ) occurs near the beginning of each simulation, while sampling of the dominant structure occurs later. This transition to the dominant structure occurs even though the non-dominant structure (14.62\%) displays an increased binding affinity (-28.46 for non-dominant $\boldsymbol{I}$ vs. $-26.46 \mathrm{kcal} / \mathrm{mol}$ for dominant $\boldsymbol{I}$ ). The sampling of these structures suggests the possibility of an energetic barrier separating these important structures. The repeated occurrence of the $\boldsymbol{I}$ dominant structure across individual trajectories suggests that it is entropically favored. Trajectory visualization indicates an RMSD- and COM-indistinguishable variation of the $\boldsymbol{I}$ dominant structure where the $(R)$ carvone group is oriented inwards towards His41, Met49, and Met165 (Figure 4B). As this variation orients the phenylthiazole groups away from the three noted residues, His $\pi$-stacking and $\mathrm{S} / \pi$ interactions are not possible in this conformation.

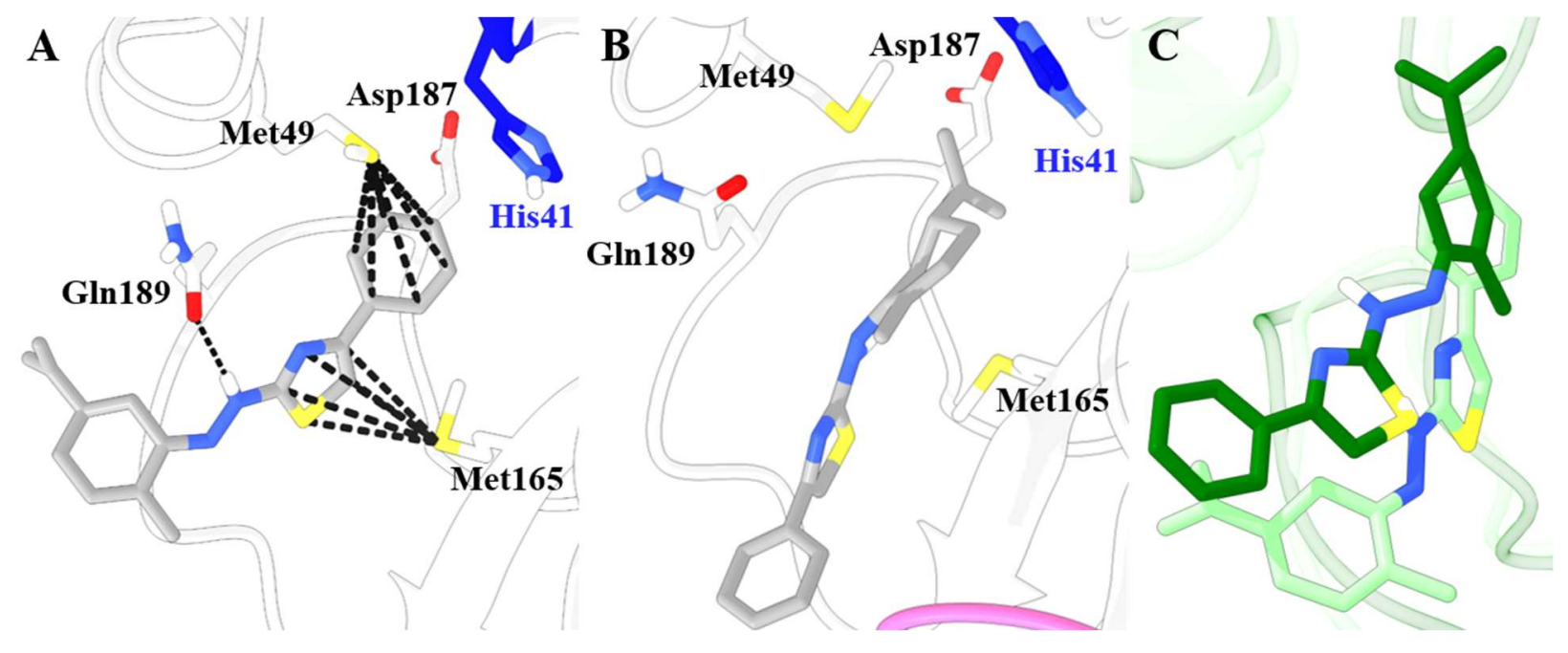

Figure 4: Compound $\boldsymbol{I}$ dominant structure variations. A. $\boldsymbol{I}$ dominant structure with phenylthiazole oriented inwards towards His41, Met49, and Met165. Potential $S / \pi$ interactions are displayed, and while a $\pi$-stacking interaction with His41 is not shown in this frame, the phenyl group location allows for these interactions across frames sampling this structure. A different orientation of this binding structure is also shown in Figure $3 \mathrm{~A}$. B. I dominant structure with (R)-carvone oriented inwards towards His41, Met49, and Met165. No potential $\pi$ interactions are noted. C. Overlay of both $\boldsymbol{I}$ average structure variations, with A shown in light green and B shown in dark green. While both of the displayed variations occupy the same space and report low RMSD and COM distance 
values of 0.86 and $1.92 \AA$ respectively, COM analysis reveals that the phenylthiazole groups are located $6.95 \AA$ apart.

Mapping regions of $\boldsymbol{I}$ and $\boldsymbol{I I I}$ to the $\mathrm{M}^{\text {Pro }}$ subsites reveals commonalities amongst the average structures of $\boldsymbol{I}$ (Figure 5A - D). All average structures of $\boldsymbol{I}$ occupy the S2 and S4 subsites. This agrees with our per-residue decomposition (Table 4) and COM distance data (Table S12) suggesting interactions with His41, Met49, Met165, and Gln189. Additionally, the reversed $\boldsymbol{I}$ dominant structure (Figure 5B), the $\boldsymbol{I}$ non-dominant structure (14.62\%) (Figure 5D), and the $\boldsymbol{I I I}$ dominant structure (Figure 5E) project their isopropyl and cyclohexane groups into the S2 pocket. Positioning of the isopropyl group into this pocket is expected due to the S2 subsite favoring occupation with Leu. As discussed above, simulations on $\boldsymbol{V}$ suggest that the positioning of the isopropyl group affects affinity and so we were not surprised to see it appear as a common binding motif in $\boldsymbol{I}$ and III; the ability to occupy the S2 subsite is likely related to the conformational preferences of the various isopropyl moieties. Notably, $\boldsymbol{I}$ is the only compound to significantly interact with the S4 subsite, while the dominant structure of $\boldsymbol{I I I}$ (Figure 5E) is the only average structure to bridge both the S1 and S2 subsites. Overall, all average structures demonstrate occupation of the previously noted important subsites for inhibitor binding. Further structural modification and optimization of these scaffolds may allow for additional interactions with various subsites and overall improved binding and inhibition. 
$\mathbf{A}$

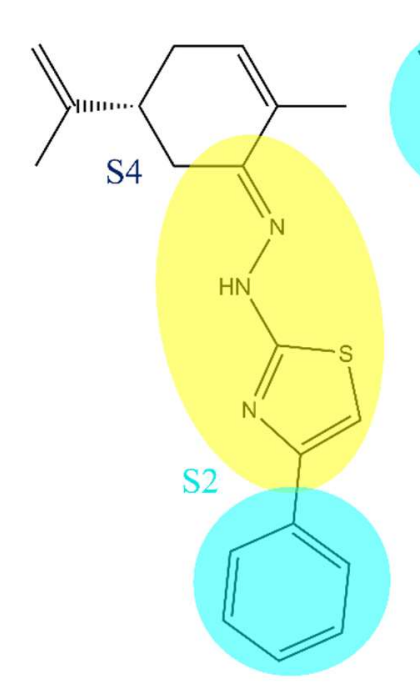

B

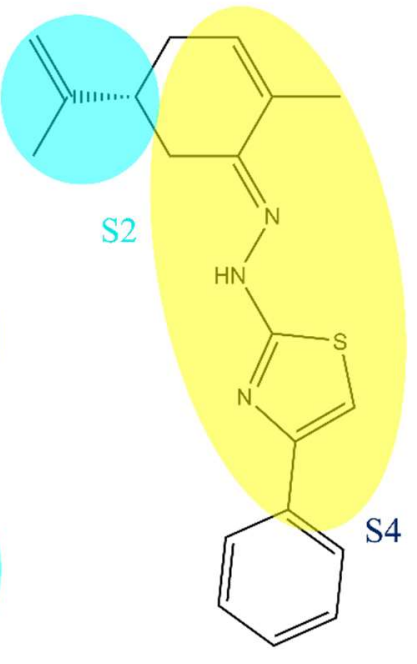

C

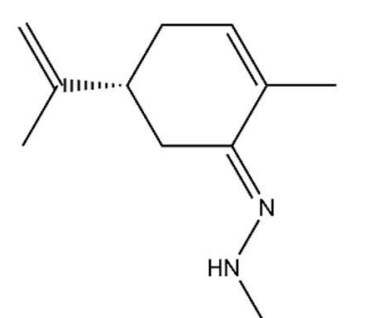

D

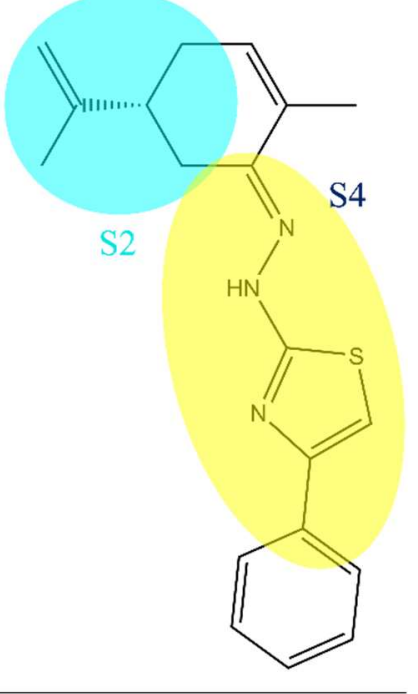

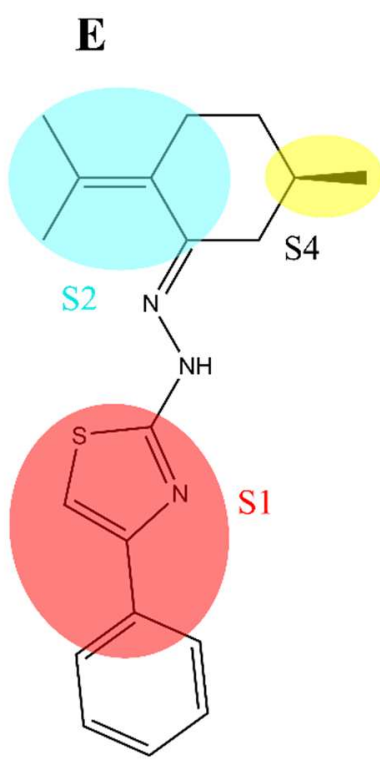

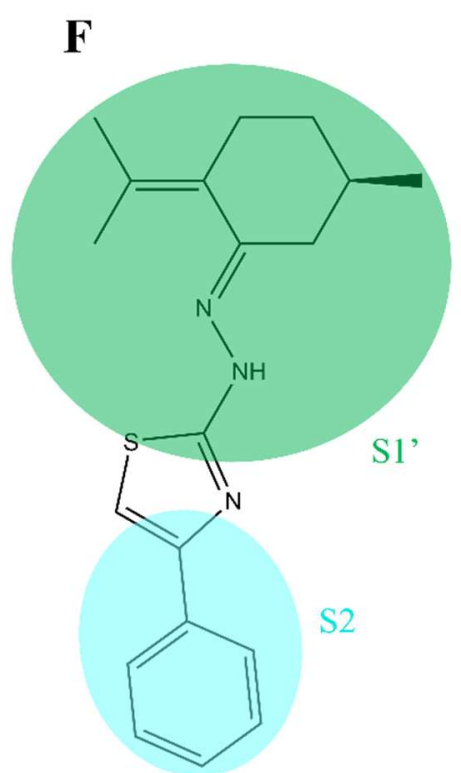

Figure 5: Compounds $\boldsymbol{I}$ and $\boldsymbol{I I I}$ average structure interactions with $\mathrm{M}^{\text {Pro }}$ pocket residues. Yellow indicates S4 pocket residues, cyan indicates S2 pocket residues, red indicates S1 pocket residues, and green indicates S1' pocket residues. Each average binding structure is displayed, with the $\boldsymbol{I}$ dominant structure and its reversal shown in A and $\mathbf{B}$, the $\boldsymbol{I}$ non-dominant structures shown in $\mathbf{C}$ and $\mathbf{D}$, and the $\boldsymbol{I I I}$ dominant and non-dominant structures shown in $\mathbf{E}$ and $\mathrm{F}$, respectively.

\section{Comparison to 5-mer Substrates}

To the best of our knowledge, there have been no previously reported, computationally-based, atomistic investigations of substrate binding to $\mathrm{M}^{\text {Pro }}$. We performed MD simulations on three 5-mer $\mathrm{M}^{\text {Pro }}$ substrates to provide a detailed binding 
comparison with the thiazole compounds. As above, truncated ensembles were produced and MM-GBSA binding free energy and per-residue decomposition analyses were conducted. Binding affinities between the VKLQA and VKLQS substrates appear highly similar, with both reporting average $\Delta \Delta \mathrm{G}$ 's of $-34.88 \mathrm{kcal} / \mathrm{mol}$. The VKLQG substrate reports a notably less favorable binding affinity and a higher percent dissociation from the catalytic site. This is expected, as coronavirus $\mathrm{M}^{\text {Pro }}$ appears to more readily select for Ser and Ala in the P1' position over Gly. ${ }^{[73,74]}$ These energies, reported in Table 5, suggest favorable binding for all three substrates, and on a scale that is relatively comparable to $\boldsymbol{I}$. (Data for each individual seed is viewable in Table S15.) It is noted that per-residue decomposition analysis indicates that the 5-mer substrates interact with many of the same residues as $\boldsymbol{I}$ (Table S16).

Table 5: 5-mer substrate full ensemble percent dissociations and truncated ensemble binding free energies. Frames encompassed by the full ensemble \% dissociation $[\mathrm{A}]$ were removed, and the remaining frames $[\mathrm{B}]$ were used to create truncated ensembles. MM-GBSA binding free energies for the frames of these truncated ensembles and their standard errors are reported.

\begin{tabular}{|c|c|c|c|}
\hline Substrate & $\begin{array}{c}\text { \% Dissociation }^{[\mathbf{A}]} / \\
\text { \% Truncated Ensemble }^{[\mathbf{B}]}\end{array}$ & \multicolumn{2}{|c|}{$\Delta \Delta \mathbf{G}(\mathbf{k c a l} / \mathbf{m o l})$} \\
\cline { 3 - 4 } & $13.0 / 87.0$ & -34.88 & 0.14 \\
\hline VKLQA & $19.2 / 80.8$ & -34.88 & 0.13 \\
\hline VKLQS & $30.1 / 69.9$ & -22.64 & 0.09 \\
\hline VKLQG & &
\end{tabular}

Normal mode calculations were performed in order to include entropic effects in our binding free energy estimations, and to allow for comparison of $\boldsymbol{I}$ and $\boldsymbol{I I I}$ to the 5 -mer substrates. These results are displayed in Table 6. Expectedly, the 5-mer substrates report greater average entropic penalties than that of the phenylthiazole compounds. Corrected binding free energies, calculated by assuming the MM-GBSA $\Delta \Delta \mathrm{G}$ to be roughly equivalent to $\Delta \mathrm{H}$ and subtracting the entropic penalty, suggests that $\boldsymbol{I}$ and $\boldsymbol{I I I}$ show greater binding affinities than the 5-mer substrates. Compound III stands out amongst the phenylthiazole compounds, with the primary and secondary truncated ensembles 
displaying corrected binding free energies of -9.07 and $-6.52 \mathrm{kcal} / \mathrm{mol}$, respectively, while compound $\boldsymbol{I}$ displays corrected binding free energies in the range of -5.4 to -5.9 $\mathrm{kcal} / \mathrm{mol}$. This further supports the promise of these compounds to serve as scaffolds for further inhibitor development.

Table 6: Truncated ensemble entropic penalties and entropy-adjusted binding free energies. Normal mode average binding entropies and their standard errors are reported. Entropy-adjusted binding free energies, used to compare binding of our novel compounds to the three $\mathrm{M}^{\text {Pro }}$ substrates, are also reported.

\begin{tabular}{|c|c|c|c|}
\hline \multirow{2}{*}{ Ensemble } & \multicolumn{2}{|c|}{$\mathbf{T} \Delta \mathbf{S}(\mathrm{kcal} / \mathbf{m o l})$} & $\Delta \Delta \mathbf{G}-\mathbf{T} \Delta \mathbf{S}$ (kcal/mol) \\
\cline { 2 - 4 } & Avg. & Std. Err. & Avg. \\
\hline $\boldsymbol{I} 1^{\mathbf{0}}$ & -19.69 & 0.58 & -5.87 \\
\hline $\boldsymbol{I} 2^{\mathbf{0}}$ & -21.44 & 0.56 & -5.39 \\
\hline $\boldsymbol{I I I} 1^{\mathbf{o}}$ & -20.44 & 0.59 & -9.07 \\
\hline $\boldsymbol{I I I} 2^{\mathbf{o}}$ & -19.57 & 0.52 & -6.52 \\
\hline VKLQA & -32.55 & 0.82 & -2.32 \\
\hline VKLQS & -32.91 & 0.76 & -1.98 \\
\hline VKLQG & -29.67 & 0.83 & 7.04 \\
\hline
\end{tabular}

\section{Conclusion}

Our experimental binding analysis suggests that previously synthesized phenylthiazole compound $\boldsymbol{I}$ is a promising scaffold for future inhibitor development. Computational analysis suggests that $\boldsymbol{I}$, along with the unsynthesized $\boldsymbol{I I I}$, pass PAINS screenings and display ADME properties in-line with known drug-like molecules. Docking analysis predicts these molecules to bind favorably to the SARS-CoV-2 $\mathrm{M}^{\text {Pro }}$ catalytic site and molecular dynamics simulations suggest prolonged interaction with the enzyme. Subsequent MM-GBSA binding free energy and per-residue decomposition calculations suggest that $\boldsymbol{I}$ and $\boldsymbol{I I I}$ experience energetically favorable binding driven predominantly by interactions with residues His41, Met49, Met165, and Gln189. Importance is also demonstrated for residues Ser144, Cys145, Glu166, and Asp187 across some of the ensemble-averaged structures. A detailed structure-activity 
comparison suggests that the orientation of the isopropyl moiety and conformation of the cyclohexane ring may be important for $\mathrm{M}^{\text {Pro }}$ binding. Trajectory visualization, per-residue decomposition and COM analysis supports the importance of specific $\pi$ interactions between the phenylthiazole moiety and $\mathrm{M}^{\text {Pro }}$. Binding is driven by $\pi$-stacking interactions with His41 and possibly S/ $\pi$ interactions with Met49 and Met165. Other notable interactions are supported, including $\mathrm{OH} / \pi$ and $\mathrm{SH} / \pi$ interactions with Ser144 and Cys145 respectively and anion/ $\pi$ interactions with Glu166. An entropically corrected binding comparison to 5-mer substrates with demonstrated experimental affinity further suggests that these compounds show promise as scaffolds for future development as SARS-CoV-2 $\mathrm{M}^{\text {Pro }}$ inhibitor drugs.

\section{Author Information}

ORCID

Justin Airas: 0000-0001-5045-9926

Catherine A. Bayas: 0000-0002-0357-2181

My Youssef Ait Itto: 0000-0003-1876-7544

M'hamed Esseffar: 0000-0002-1675-5155

Julie A. Pollock: 0000-0003-0153-9991

Carol A. Parish: 0000-0003-2878-3070

\section{Acknowledgements}

This research was supported by funding from the National Science Foundation (Grant CHE-18800014), the Donors of the American Chemical Society Petroleum Research Fund and the Floyd D. and Elisabeth S. Gottwald Endowment. J.A. and C.A.B. were recipients of a summer fellowship from the Puryear-Topham-Pierce-Gupton endowment from the Department of Chemistry at the University of Richmond. J.A. was also a recipient of summer support from the University of Richmond Integrated and Inclusive Science program, and the Arts and Sciences Undergraduate Research Committee.

\section{References}


[1] Zhu, N.; Zhang, D.; Wang, W.; Li, X.; Yang, B.; Song, J.; Zhao, X.; Huang, B.; Shi, W.; Lu, R.; Niu, P.; Zhan, F.; Ma, X.; Wang, D.; Xu, W.; Wu, G.; Gao, G. F.; Tan, W. A Novel Coronavirus from Patients with Pneumonia in China, 2019. N Engl J Med 2020, 382 (8), 727-733. https://doi.org/10.1056/NEJMoa2001017.

[2] Li, Q.; Guan, X.; Wu, P.; Wang, X.; Zhou, L.; Tong, Y.; Ren, R.; Leung, K. S. M.; Lau, E. H. Y.; Wong, J. Y.; Xing, X.; Xiang, N.; Wu, Y.; Li, C.; Chen, Q.; Li, D.; Liu, T.; Zhao, J.; Liu, M.; Tu, W.; Chen, C.; Jin, L.; Yang, R.; Wang, Q.; Zhou, S.; Wang, R.; Liu, H.; Luo, Y.; Liu, Y.; Shao, G.; Li, H.; Tao, Z.; Yang, Y.; Deng, Z.; Liu, B.; Ma, Z.; Zhang, Y.; Shi, G.; Lam, T. T. Y.; Wu, J. T.; Gao, G. F.; Cowling, B. J.; Yang, B.; Leung, G. M.; Feng, Z. Early Transmission Dynamics in Wuhan, China, of Novel Coronavirus-Infected Pneumonia. N Engl J Med 2020, 382 (13), 1199-1207. https://doi.org/10.1056/NEJMoa2001316.

[3] Zhou, P.; Yang, X.-L.; Wang, X.-G.; Hu, B.; Zhang, L.; Zhang, W.; Si, H.-R.; Zhu, Y.; Li, B.; Huang, C.L.; Chen, H.-D.; Chen, J.; Luo, Y.; Guo, H.; Jiang, R.-D.; Liu, M.-Q.; Chen, Y.; Shen, X.-R.; Wang, X.; Zheng, X.S.; Zhao, K.; Chen, Q.-J.; Deng, F.; Liu, L.-L.; Yan, B.; Zhan, F.-X.; Wang, Y.-Y.; Xiao, G.-F.; Shi, Z.-L. A Pneumonia Outbreak Associated with a New Coronavirus of Probable Bat Origin. Nature 2020, 579 (7798), 270 273. https://doi.org/10.1038/s41586-020-2012-7.

[4] Wu, F.; Zhao, S.; Yu, B.; Chen, Y.-M.; Wang, W.; Song, Z.-G.; Hu, Y.; Tao, Z.-W.; Tian, J.-H.; Pei, Y.-Y.; Yuan, M.-L.; Zhang, Y.-L.; Dai, F.-H.; Liu, Y.; Wang, Q.-M.; Zheng, J.-J.; Xu, L.; Holmes, E. C.; Zhang, Y.-Z. A New Coronavirus Associated with Human Respiratory Disease in China. Nature 2020, 579 (7798), 265-269. https://doi.org/10.1038/s41586-020-2008-3.

[5] Velavan, T. P.; Meyer, C. G. The COVID-19 Epidemic. Trop Med Int Health 2020, 25 (3), 278-280. https://doi.org/10.1111/tmi.13383.

[6] Arons, M. M.; Hatfield, K. M.; Reddy, S. C.; Kimball, A.; James, A.; Jacobs, J. R.; Taylor, J.; Spicer, K.; Bardossy, A. C.; Oakley, L. P.; Tanwar, S.; Dyal, J. W.; Harney, J.; Chisty, Z.; Bell, J. M.; Methner, M.; Paul, P.; Carlson, C. M.; McLaughlin, H. P.; Thornburg, N.; Tong, S.; Tamin, A.; Tao, Y.; Uehara, A.; Harcourt, J.; Clark, S.; Brostrom-Smith, C.; Page, L. C.; Kay, M.; Lewis, J.; Montgomery, P.; Stone, N. D.; Clark, T. A.; Honein, M. A.; Duchin, J. S.; Jernigan, J. A. Presymptomatic SARS-CoV-2 Infections and Transmission in a Skilled Nursing Facility. N Engl J Med 2020, 382 (22), 2081-2090. https://doi.org/10.1056/NEJMoa2008457.

[7] Huang, C.; Wang, Y.; Li, X.; Ren, L.; Zhao, J.; Hu, Y.; Zhang, L.; Fan, G.; Xu, J.; Gu, X.; Cheng, Z.; Yu, T.; Xia, J.; Wei, Y.; Wu, W.; Xie, X.; Yin, W.; Li, H.; Liu, M.; Xiao, Y.; Gao, H.; Guo, L.; Xie, J.; Wang, G.; Jiang, R.; Gao, Z.; Jin, Q.; Wang, J.; Cao, B. Clinical Features of Patients Infected with 2019 Novel Coronavirus in Wuhan, China. The Lancet 2020, 395 (10223), 497-506. https://doi.org/10.1016/S0140-6736(20)30183-5.

[8] Spinato, G.; Fabbris, C.; Polesel, J.; Cazzador, D.; Borsetto, D.; Hopkins, C.; Boscolo-Rizzo, P. Alterations in Smell or Taste in Mildly Symptomatic Outpatients With SARS-CoV-2 Infection. JAMA 2020, 323 (20), 20892090. https://doi.org/10.1001/jama.2020.6771. 
[9] Yang, W.; Kandula, S.; Huynh, M.; Greene, S. K.; Van Wye, G.; Li, W.; Chan, H. T.; McGibbon, E.; Yeung, A.; Olson, D.; Fine, A.; Shaman, J. Estimating the Infection-Fatality Risk of SARS-CoV-2 in New York City during the Spring 2020 Pandemic Wave: A Model-Based Analysis. The Lancet Infectious Diseases 2021, 21 (2), 203-212. https://doi.org/10.1016/S1473-3099(20)30769-6.

[10] Ssentongo, P.; Ssentongo, A. E.; Heilbrunn, E. S.; Ba, D. M.; Chinchilli, V. M. Association of Cardiovascular Disease and 10 Other Pre-Existing Comorbidities with COVID-19 Mortality: A Systematic Review and Meta-Analysis. PLOS ONE 2020, 15 (8), e0238215. https://doi.org/10.1371/journal.pone.0238215.

[11] Gao, Y.; Yan, L.; Huang, Y.; Liu, F.; Zhao, Y.; Cao, L.; Wang, T.; Sun, Q.; Ming, Z.; Zhang, L.; Ge, J.; Zheng, L.; Zhang, Y.; Wang, H.; Zhu, Y.; Zhu, C.; Hu, T.; Hua, T.; Zhang, B.; Yang, X.; Li, J.; Yang, H.; Liu, Z.; Xu, W.; Guddat, L. W.; Wang, Q.; Lou, Z.; Rao, Z. Structure of the RNA-Dependent RNA Polymerase from COVID-19 Virus. Science 2020, 368 (6492), 779. https://doi.org/10.1126/science.abb7498.

[12] Jin, Z.; Du, X.; Xu, Y.; Deng, Y.; Liu, M.; Zhao, Y.; Zhang, B.; Li, X.; Zhang, L.; Peng, C.; Duan, Y.; Yu, J.; Wang, L.; Yang, K.; Liu, F.; Jiang, R.; Yang, X.; You, T.; Liu, X.; Yang, X.; Bai, F.; Liu, H.; Liu, X.; Guddat, L. W.; Xu, W.; Xiao, G.; Qin, C.; Shi, Z.; Jiang, H.; Rao, Z.; Yang, H. Structure of Mpro from SARS-CoV-2 and Discovery of Its Inhibitors. Nature 2020, 582 (7811), 289-293. https://doi.org/10.1038/s41586-020-2223-y.

[13] Beigel, J. H.; Tomashek, K. M.; Dodd, L. E.; Mehta, A. K.; Zingman, B. S.; Kalil, A. C.; Hohmann, E.; Chu, H. Y.; Luetkemeyer, A.; Kline, S.; Lopez de Castilla, D.; Finberg, R. W.; Dierberg, K.; Tapson, V.; Hsieh, L.; Patterson, T. F.; Paredes, R.; Sweeney, D. A.; Short, W. R.; Touloumi, G.; Lye, D. C.; Ohmagari, N.; Oh, M.-D.; Ruiz-Palacios, G. M.; Benfield, T.; Fätkenheuer, G.; Kortepeter, M. G.; Atmar, R. L.; Creech, C. B.; Lundgren, J.; Babiker, A. G.; Pett, S.; Neaton, J. D.; Burgess, T. H.; Bonnett, T.; Green, M.; Makowski, M.; Osinusi, A.; Nayak, S.; Lane, H. C.; ACTT-1 Study Group Members. Remdesivir for the Treatment of Covid-19 - Final Report. N Engl J Med 2020, 383 (19), 1813-1826. https://doi.org/10.1056/NEJMoa2007764.

[14] Ullrich, S.; Nitsche, C. The SARS-CoV-2 Main Protease as Drug Target. Bioorganic \& Medicinal Chemistry Letters 2020, 30 (17), 127377. https://doi.org/10.1016/j.bmcl.2020.127377.

[15] Zhang, L.; Lin, D.; Sun, X.; Curth, U.; Drosten, C.; Sauerhering, L.; Becker, S.; Rox, K.; Hilgenfeld, R. Crystal Structure of SARS-CoV-2 Main Protease Provides a Basis for Design of Improved $\alpha$-Ketoamide Inhibitors. Science 2020, 368 (6489), 409. https://doi.org/10.1126/science.abb3405.

[16] Seth, S.; Batra, J.; Srinivasan, S. COVID-19: Targeting Proteases in Viral Invasion and Host Immune Response. Front Mol Biosci 2020, 7, 215-215. https://doi.org/10.3389/fmolb.2020.00215.

[17] Stoddard, S. V.; Stoddard, S. D.; Oelkers, B. K.; Fitts, K.; Whalum, K.; Whalum, K.; Hemphill, A. D.; Manikonda, J.; Martinez, L. M.; Riley, E. G.; Roof, C. M.; Sarwar, N.; Thomas, D. M.; Ulmer, E.; Wallace, F. E.; Pandey, P.; Roy, S. Optimization Rules for SARS-CoV-2 Mpro Antivirals: Ensemble Docking and Exploration of the Coronavirus Protease Active Site. Viruses 2020, 12 (9). https://doi.org/10.3390/v12090942. 
[18] Amin, Sk. A.; Banerjee, S.; Singh, S.; Qureshi, I. A.; Gayen, S.; Jha, T. First Structure-Activity Relationship Analysis of SARS-CoV-2 Virus Main Protease (Mpro) Inhibitors: An Endeavor on COVID-19 Drug Discovery. Molecular Diversity 2021. https://doi.org/10.1007/s11030-020-10166-3.

[19] Wang, Z.; Zhao, Y.; Wang, Q.; Xing, Y.; Feng, L.; Kong, J.; Peng, C.; Zhang, L.; Yang, H.; Lu, M. Identification of Proteasome and Caspase Inhibitors Targeting SARS-CoV-2 Mpro. Signal Transduction and Targeted Therapy 2021, 6 (1), 214. https://doi.org/10.1038/s41392-021-00639-8.

[20] Mohamed, N. M.; Ali, E. M. H.; AboulMagd, A. M. Ligand-Based Design, Molecular Dynamics and ADMET Studies of Suggested SARS-CoV-2 Mpro Inhibitors. RSC Adv. 2021, 11 (8), 4523-4538. https://doi.org/10.1039/D0RA10141A.

[21] Breidenbach, J.; Lemke, C.; Pillaiyar, T.; Schäkel, L.; Al Hamwi, G.; Diett, M.; Gedschold, R.; Geiger, N.; Lopez, V.; Mirza, S.; Namasivayam, V.; Schiedel, A. C.; Sylvester, K.; Thimm, D.; Vielmuth, C.; Phuong Vu, L.; Zyulina, M.; Bodem, J.; Gütschow, M.; Müller, C. E. Targeting the Main Protease of SARS-CoV-2: From the Establishment of High Throughput Screening to the Design of Tailored Inhibitors. Angewandte Chemie International Edition 2021, 60 (18), 10423-10429. https://doi.org/10.1002/anie.202016961.

[22] Gimeno, A.; Mestres-Truyol, J.; Ojeda-Montes, M. J.; Macip, G.; Saldivar-Espinoza, B.; Cereto-Massagué, A.; Pujadas, G.; Garcia-Vallvé, S. Prediction of Novel Inhibitors of the Main Protease (M-pro) of SARS-CoV-2 through Consensus Docking and Drug Reposition. International Journal of Molecular Sciences 2020, 21 (11). https://doi.org/10.3390/ijms21113793.

[23] Gossen, J.; Albani, S.; Hanke, A.; Joseph, B. P.; Bergh, C.; Kuzikov, M.; Costanzi, E.; Manelfi, C.; Storici, P.; Gribbon, P.; Beccari, A. R.; Talarico, C.; Spyrakis, F.; Lindahl, E.; Zaliani, A.; Carloni, P.; Wade, R. C.; Musiani, F.; Kokh, D. B.; Rossetti, G. A Blueprint for High Affinity SARS-CoV-2 Mpro Inhibitors from ActivityBased Compound Library Screening Guided by Analysis of Protein Dynamics. ACS Pharmacol. Transl. Sci. 2021, 4 (3), 1079-1095. https://doi.org/10.1021/acsptsci.0c00215.

[24] Yoshino, R.; Yasuo, N.; Sekijima, M. Identification of Key Interactions between SARS-CoV-2 Main Protease and Inhibitor Drug Candidates. Scientific Reports 2020, 10 (1), 12493. https://doi.org/10.1038/s41598-020$\underline{69337-9}$.

[25] Ton, A.-T.; Gentile, F.; Hsing, M.; Ban, F.; Cherkasov, A. Rapid Identification of Potential Inhibitors of SARS-CoV-2 Main Protease by Deep Docking of 1.3 Billion Compounds. Molecular Informatics 2020, 39 (8), 2000028. https://doi.org/10.1002/minf.202000028.

[26] Yang, H.; Xie, W.; Xue, X.; Yang, K.; Ma, J.; Liang, W.; Zhao, Q.; Zhou, Z.; Pei, D.; Ziebuhr, J.; Hilgenfeld, R.; Yuen, K. Y.; Wong, L.; Gao, G.; Chen, S.; Chen, Z.; Ma, D.; Bartlam, M.; Rao, Z. Design of WideSpectrum Inhibitors Targeting Coronavirus Main Proteases. PLOS Biology 2005, 3 (10), e324. https://doi.org/10.1371/journal.pbio.0030324. 
[27] Hung Hui-Chen; Ke Yi-Yu; Huang Sheng Yu; Huang Peng-Nien; Kung Yu-An; Chang Teng-Yuan; Yen Kuei-Jung; Peng Tzu-Ting; Chang Shao-En; Huang Chin-Ting; Tsai Ya-Ru; Wu Szu-Huei; Lee Shiow-Ju; Lin Jiunn-Horng; Liu Bing-Sin; Sung Wang-Chou; Shih Shin-Ru; Chen Chiung-Tong; Hsu John Tsu-An. Discovery of M Protease Inhibitors Encoded by SARS-CoV-2. Antimicrobial Agents and Chemotherapy 64 (9), e00872-20. https://doi.org/10.1128/AAC.00872-20.

[28] Arafet, K.; Serrano-Aparicio, N.; Lodola, A.; Mulholland, A. J.; González, F. V.; Świderek, K.; Moliner, V. Mechanism of Inhibition of SARS-CoV-2 Mpro by N3 Peptidyl Michael Acceptor Explained by QM/MM Simulations and Design of New Derivatives with Tunable Chemical Reactivity. Chem. Sci. 2021, 12 (4), $1433-$ 1444. https://doi.org/10.1039/D0SC06195F.

[29] Fu, L.; Ye, F.; Feng, Y.; Yu, F.; Wang, Q.; Wu, Y.; Zhao, C.; Sun, H.; Huang, B.; Niu, P.; Song, H.; Shi, Y.; Li, X.; Tan, W.; Qi, J.; Gao, G. F. Both Boceprevir and GC376 Efficaciously Inhibit SARS-CoV-2 by Targeting Its Main Protease. Nature Communications 2020, 11 (1), 4417. https://doi.org/10.1038/s41467-020-18233-x.

[30] Ma, C.; Sacco, M. D.; Hurst, B.; Townsend, J. A.; Hu, Y.; Szeto, T.; Zhang, X.; Tarbet, B.; Marty, M. T.; Chen, Y.; Wang, J. Boceprevir, GC-376, and Calpain Inhibitors II, XII Inhibit SARS-CoV-2 Viral Replication by Targeting the Viral Main Protease. Cell Research 2020, 30 (8), 678-692. https://doi.org/10.1038/s41422-020-0356$\underline{\mathrm{z}}$.

[31] Someshwar Pola ED1 - Ravi Varala. Significance of Thiazole-Based Heterocycles for Bioactive Systems. In Scope of Selective Heterocycles from Organic and Pharmaceutical Perspective; IntechOpen: Rijeka, 2016; p Ch. 1. https://doi.org/10.5772/62077.

[32] Ayati, A.; Emami, S.; Asadipour, A.; Shafiee, A.; Foroumadi, A. Recent Applications of 1,3-Thiazole Core Structure in the Identification of New Lead Compounds and Drug Discovery. European Journal of Medicinal Chemistry 2015, 97, 699-718. https://doi.org/10.1016/j.ejmech.2015.04.015.

[33] Seck, I.; Nguemo, F. Triazole, Imidazole, and Thiazole-Based Compounds as Potential Agents against Coronavirus. Results in Chemistry 2021, 3, 100132. https://doi.org/10.1016/j.rechem.2021.100132.

[34] Freidel, M. R.; Armen, R. S. Mapping Major SARS-CoV-2 Drug Targets and Assessment of Druggability Using Computational Fragment Screening: Identification of an Allosteric Small-Molecule Binding Site on the Nsp13 Helicase. PLOS ONE 2021, 16 (2), e0246181. https://doi.org/10.1371/journal.pone.0246181.

[35] Zhang, S.-G.; Liang, C.-G.; Zhang, W.-H. Recent Advances in Indazole-Containing Derivatives: Synthesis and Biological Perspectives. Molecules 2018, 23 (11), 2783- 2823. https://doi.org/10.3390/molecules23112783.

[36] Gao, K.; Nguyen, D. D.; Chen, J.; Wang, R.; Wei, G.-W. Repositioning of 8565 Existing Drugs for COVID-19. J Phys Chem Lett 2020, 11 (13), 5373-5382. https://doi.org/10.1021/acs.jpclett.0c01579. 
[37] N'Ait Ousidi, A.; Itto, M. Y. A.; Auhmani, A.; Loubidi, M.; Riahi, A.; Daran, J.-C.; Esseffar, M.; Parish, C. A. Diastereoselective Synthesis of New Thiazolyl-Indazole Derivatives from R-Carvone: A Combined Experimental and Theoretical Study. Tetrahedron 2021, 78, 131830. https://doi.org/10.1016/j.tet.2020.131830.

[38] Hu, Y.; Stumpfe, D.; Bajorath, J. Computational Exploration of Molecular Scaffolds in Medicinal Chemistry. J. Med. Chem. 2016, 59 (9), 4062-4076. https://doi.org/10.1021/acs.jmedchem.5b01746.

[39] Baell, J. B.; Holloway, G. A. New Substructure Filters for Removal of Pan Assay Interference Compounds (PAINS) from Screening Libraries and for Their Exclusion in Bioassays. J. Med. Chem. 2010, 53 (7), 2719-2740. https://doi.org/10.1021/jm901137j.

[40] Schrödinger Release 2019-3: QikProp, Schrödinger, LLC, New York, NY, 2019.

[41] Berman, H. M.; Westbrook, J.; Feng, Z.; Gilliland, G.; Bhat, T. N.; Weissig, H.; Shindyalov, I. N.; Bourne, P. E. The Protein Data Bank. Nucleic Acids Research 2000, 28 (1), 235-242. https://doi.org/10.1093/nar/28.1.235.

[42] Schrödinger Release 2019-3: Protein Preparation Wizard; Epik, Schrödinger, LLC: New York, NY, 2016. Impact, Schrödinger, LLC, New York, NY, 2016; Prime, Schrödinger, LLC, New York, NY, 2019.

[43] Søndergaard, C. R.; Olsson, M. H. M.; Rostkowski, M.; Jensen, J. H. Improved Treatment of Ligands and Coupling Effects in Empirical Calculation and Rationalization of PKa Values. J. Chem. Theory Comput. 2011, 7 (7), 2284-2295. https://doi.org/10.1021/ct200133y.

[44] Olsson, M. H. M.; Søndergaard, C. R.; Rostkowski, M.; Jensen, J. H. PROPKA3: Consistent Treatment of Internal and Surface Residues in Empirical PKa Predictions. J. Chem. Theory Comput. 2011, 7 (2), 525-537. https://doi.org/10.1021/ct100578z.

[45] Harder, E.; Damm, W.; Maple, J.; Wu, C.; Reboul, M.; Xiang, J. Y.; Wang, L.; Lupyan, D.; Dahlgren, M. K.; Knight, J. L.; Kaus, J. W.; Cerutti, D. S.; Krilov, G.; Jorgensen, W. L.; Abel, R.; Friesner, R. A. OPLS3: A Force Field Providing Broad Coverage of Drug-like Small Molecules and Proteins. J. Chem. Theory Comput. 2016, 12 (1), 281-296. https://doi.org/10.1021/acs.jctc.5b00864.

[46] Wang, J.; Wolf, R. M.; Caldwell, J. W.; Kollman, P. A.; Case, D. A. Development and Testing of a General Amber Force Field. Journal of Computational Chemistry 2004, 25 (9), 1157-1174.

https://doi.org/10.1002/jcc.20035.

[47] Hanwell, M. D.; Curtis, D. E.; Lonie, D. C.; Vandermeersch, T.; Zurek, E.; Hutchison, G. R. Avogadro: An Advanced Semantic Chemical Editor, Visualization, and Analysis Platform. Journal of Cheminformatics 2012, 4 (1), 17. https://doi.org/10.1186/1758-2946-4-17.

[48] Gaussian 16, Revision B.01, M. J. Frisch, G. W. Trucks, H. B. Schlegel, G. E. Scuseria, M. A. Robb, J. R. Cheeseman, G. Scalmani, V. Barone, G. A. Petersson, H. Nakatsuji, X. Li, M. Caricato, A. V. Marenich, J. Bloino, B. G. Janesko, R. Gomperts, B. Mennucci, H. P. Hratchian, J. V. Ortiz, A. F. Izmaylov, J. L. Sonnenberg, D. 
Williams-Young, F. Ding, F. Lipparini, F. Egidi, J. Goings, B. Peng, A. Petrone, T. Henderson, D. Ranasinghe, V. G. Zakrzewski, J. Gao, N. Rega, G. Zheng, W. Liang, M. Hada, M. Ehara, K. Toyota, R. Fukuda, J. Hasegawa, M. Ishida, T. Nakajima, Y. Honda, O. Kitao, H. Nakai, T. Vreven, K. Throssell, J. A. Montgomery, Jr., J. E. Peralta, F. Ogliaro, M. J. Bearpark, J. J. Heyd, E. N. Brothers, K. N. Kudin, V. N. Staroverov, T. A. Keith, R. Kobayashi, J. Normand, K. Raghavachari, A. P. Rendell, J. C. Burant, S. S. Iyengar, J. Tomasi, M. Cossi, J. M. Millam, M. Klene, C. Adamo, R. Cammi, J. W. Ochterski, R. L. Martin, K. Morokuma, O. Farkas, J. B. Foresman, and D. J. Fox, Gaussian, Inc., Wallingford CT, 2016.

[49] Friesner, R. A.; Banks, J. L.; Murphy, R. B.; Halgren, T. A.; Klicic, J. J.; Mainz, D. T.; Repasky, M. P.; Knoll, E. H.; Shelley, M.; Perry, J. K.; Shaw, D. E.; Francis, P.; Shenkin, P. S. Glide: A New Approach for Rapid, Accurate Docking and Scoring. 1. Method and Assessment of Docking Accuracy. J. Med. Chem. 2004, 47 (7), 1739-1749. https://doi.org/10.1021/jm0306430.

[50] Halgren, T. A.; Murphy, R. B.; Friesner, R. A.; Beard, H. S.; Frye, L. L.; Pollard, W. T.; Banks, J. L. Glide: A New Approach for Rapid, Accurate Docking and Scoring. 2. Enrichment Factors in Database Screening. $J$. Med. Chem. 2004, 47 (7), 1750-1759. https://doi.org/10.1021/jm030644s.

[51] Rut, W.; Groborz, K.; Zhang, L.; Sun, X.; Zmudzinski, M.; Pawlik, B.; Wang, X.; Jochmans, D.; Neyts, J.; Młynarski, W.; Hilgenfeld, R.; Drag, M. SARS-CoV-2 Mpro Inhibitors and Activity-Based Probes for PatientSample Imaging. Nature Chemical Biology 2021, 17 (2), 222-228. https://doi.org/10.1038/s41589-020-00689-z.

[52] Schrödinger Release 2019-3: Maestro, Schrödinger, LLC, New York, NY, 2021.

[53] Anand, K.; Ziebuhr, J.; Wadhwani, P.; Mesters, J. R.; Hilgenfeld, R. Coronavirus Main Proteinase (3CL ${ }^{\text {pro }}$ ) Structure: Basis for Design of Anti-SARS Drugs. Science 2003, 300 (5626), 1763. https://doi.org/10.1126/science.1085658.

[54] Pettersen, E. F.; Goddard, T. D.; Huang, C. C.; Couch, G. S.; Greenblatt, D. M.; Meng, E. C.; Ferrin, T. E. UCSF Chimera-A Visualization System for Exploratory Research and Analysis. Journal of Computational Chemistry 2004, 25 (13), 1605-1612. https://doi.org/10.1002/jcc.20084.

[55] D.A. Case, I. Y. B.-S., S.R. Brozell, D.S. Cerutti, T.E. Cheatham, III, V.W.D. Cruzeiro, T.A. Darden, R.E. Duke, D. Ghoreishi, M.K. Gilson, H. Gohlke, A.W. Goetz, D. Greene, R Harris, N. Homeyer, S. Izadi, A. Kovalenko, T. Kurtzman, T.S. Lee, S. LeGrand, P. Li, C. Lin, J. Liu, T. Luchko, R. Luo, D.J. Mermelstein, K.M. Merz, Y. Miao, G. Monard, C. Nguyen, H. Nguyen, I. Omelyan, A. Onufriev, F. Pan, R. Qi, D.R. Roe, A. Roitberg, C. Sagui, S. Schott-Verdugo, J. Shen, C.L. Simmerling, J. Smith, R. Salomon-Ferrer, J. Swails, R.C. Walker, J. Wang, H. Wei, R.M. Wolf, X. Wu, L. Xiao, D.M. York and P.A. Kollman, AMBER 2018, University of California, San Francisco, 2018.

[56] Maier, J. A.; Martinez, C.; Kasavajhala, K.; Wickstrom, L.; Hauser, K. E.; Simmerling, C. ff14SB: Improving the Accuracy of Protein Side Chain and Backbone Parameters from ff99SB. J. Chem. Theory Comput. 2015, 11 (8), 3696-3713. https://doi.org/10.1021/acs.jctc.5b00255. 
[57] Wang, J.; Wang, W.; Kollman, P. A.; Case, D. A. Automatic Atom Type and Bond Type Perception in Molecular Mechanical Calculations. Journal of Molecular Graphics and Modelling 2006, 25 (2), 247-260. https://doi.org/10.1016/j.jmgm.2005.12.005.

[58] Jakalian, A.; Bush, B. L.; Jack, D. B.; Bayly, C. I. Fast, Efficient Generation of High-Quality Atomic Charges. AM1-BCC Model: I. Method. Journal of Computational Chemistry 2000, 21 (2), 132-146. https://doi.org/10.1002/(SICI)1096-987X(20000130)21:2<132::AID-JCC5>3.0.CO;2-P.

[59] Jakalian, A.; Jack, D. B.; Bayly, C. I. Fast, Efficient Generation of High-Quality Atomic Charges. AM1BCC Model: II. Parameterization and Validation. Journal of Computational Chemistry 2002, 23 (16), 1623-1641. https://doi.org/10.1002/jcc.10128.

[60] Jorgensen, W. L.; Madura, J. D. Quantum and Statistical Mechanical Studies of Liquids. 25. Solvation and Conformation of Methanol in Water. J. Am. Chem. Soc. 1983, 105 (6), 1407-1413.

https://doi.org/10.1021/ja00344a001.

[61] Götz, A. W.; Williamson, M. J.; Xu, D.; Poole, D.; Le Grand, S.; Walker, R. C. Routine Microsecond Molecular Dynamics Simulations with AMBER on GPUs. 1. Generalized Born. J Chem Theory Comput 2012, 8 (5), 1542-1555. https://doi.org/10.1021/ct200909j.

[62] Salomon-Ferrer, R.; Götz, A. W.; Poole, D.; Le Grand, S.; Walker, R. C. Routine Microsecond Molecular Dynamics Simulations with AMBER on GPUs. 2. Explicit Solvent Particle Mesh Ewald. J. Chem. Theory Comput. 2013, 9 (9), 3878-3888. https://doi.org/10.1021/ct400314y.

[63] Goddard, T. D.; Huang, C. C.; Meng, E. C.; Pettersen, E. F.; Couch, G. S.; Morris, J. H.; Ferrin, T. E. UCSF ChimeraX: Meeting Modern Challenges in Visualization and Analysis. Protein Science 2018, 27 (1), 14-25. https://doi.org/10.1002/pro.3235.

[64] Miller, B. R.; McGee, T. D.; Swails, J. M.; Homeyer, N.; Gohlke, H.; Roitberg, A. E. MMPBSA.Py: An Efficient Program for End-State Free Energy Calculations. J. Chem. Theory Comput. 2012, 8 (9), 3314-3321. https://doi.org/10.1021/ct300418h.

[65] Hou, T.; Wang, J.; Li, Y.; Wang, W. Assessing the Performance of the MM/PBSA and MM/GBSA Methods. 1. The Accuracy of Binding Free Energy Calculations Based on Molecular Dynamics Simulations. $J$. Chem. Inf. Model. 2011, 51 (1), 69-82. https://doi.org/10.1021/ci100275a.

[66] Meurisse, R.; Brasseur, R.; Thomas, A. Aromatic Side-Chain Interactions in Proteins. Near- and FarSequence His-X Pairs. Biochimica et Biophysica Acta (BBA) - Proteins and Proteomics 2003, 1649 (1), 85-96. https://doi.org/10.1016/S1570-9639(03)00161-4.

[67] Philip, V.; Harris, J.; Adams, R.; Nguyen, D.; Spiers, J.; Baudry, J.; Howell, E. E.; Hinde, R. J. A Survey of Aspartate-Phenylalanine and Glutamate-Phenylalanine Interactions in the Protein Data Bank: Searching for Anion- $\pi$ Pairs. Biochemistry 2011, 50 (14), 2939-2950. https://doi.org/10.1021/bi200066k. 
[68] Tsuzuki, S.; Honda, K.; Uchimaru, T.; Mikami, M.; Tanabe, K. Origin of the Attraction and Directionality of the $\mathrm{NH} / \pi$ Interaction: Comparison with $\mathrm{OH} / \pi$ and $\mathrm{CH} / \pi$ Interactions. J. Am. Chem. Soc. 2000, 122 (46), 1145011458. https://doi.org/10.1021/ja001901a.

[69] Forbes, C. R.; Sinha, S. K.; Ganguly, H. K.; Bai, S.; Yap, G. P. A.; Patel, S.; Zondlo, N. J. Insights into Thiol-Aromatic Interactions: A Stereoelectronic Basis for $\mathrm{S}-\mathrm{H} / \pi$ Interactions. J. Am. Chem. Soc. 2017, 139 (5), 1842-1855. https://doi.org/10.1021/jacs.6b08415.

[70] Ringer, A. L.; Senenko, A.; Sherrill, C. D. Models of S/ $\pi$ Interactions in Protein Structures: Comparison of the H2S-Benzene Complex with PDB Data. Protein Science 2007, 16 (10), 2216-2223. https://doi.org/10.1110/ps.073002307.

[71] Reid, K. S. C.; Lindley, P. F.; Thornton, J. M. Sulphur-Aromatic Interactions in Proteins. FEBS Letters 1985, 190 (2), 209-213. https://doi.org/10.1016/0014-5793(85)81285-0.

[72] Ellenbarger, J. F.; Krieger, I. V.; Huang, H.; Gómez-Coca, S.; Ioerger, T. R.; Sacchettini, J. C.; Wheeler, S. E.; Dunbar, K. R. Anion- $\pi$ Interactions in Computer-Aided Drug Design: Modeling the Inhibition of Malate Synthase by Phenyl-Diketo Acids. J. Chem. Inf. Model. 2018, 58 (10), 2085-2091. https://doi.org/10.1021/acs.jcim.8b00417.

[73] Hegyi, A.; Ziebuhr, J. Conservation of Substrate Specificities among Coronavirus Main Proteases. Journal of General Virology, 2002, 83, 595-599. https://doi.org/10.1099/0022-1317-83-3-595.

[74] Ziebuhr, J.; Snijder, E. J.; Gorbalenya, A. E. Virus-Encoded Proteinases and Proteolytic Processing in the Nidovirales. Journal of General Virology, 2000, 81, 853-879. https://doi.org/10.1099/0022-1317-81-4-853. 